\title{
CSHP Professional Practice Conference 2015: Poster Abstracts / Conférence sur la pratique professionnelle 2015 de la SCPH : Résumés des affiches
}

\section{Sunday, February 1, 2015 • Dimanche $1^{\text {er }}$ février 2015 \\ Facilitated Poster Sessions: Discussion of original research, award-winning projects, and pharmacy practice projects \\ Séance animée de présentations par affiches: Discussions sur des projets de recherche originale, des projets primes, et des projets dans le domaine de la pratique pharmaceutique}

\section{Infectious Diseases}

1. Acute Kidney Injury with Tobramycin-Impregnated Bone Cement Spacers in Prosthetic Joint Infections: A Controlled Study

2. Comparison of the Accuracy of 4 Sets of Criteria at Predicting Presence of Pseudomonas aeruginosa in Patients Admitted for Pneumonia

3. Trends of Antibiotic Use in the Inpatient Acute Care Setting: Is There Evidence of Seasonality?

4. Efficacy and Safety of Atazanavir plus Raltegravir Dual Therapy in Treatment-Experienced HIV-1 Infected Patients

5. Outcomes in Documented Pseudomonas aeruginosa Bacteremia Treated with Intermittent Infusion Intravenous Ceftazidime, Meropenem, and Piperacillin/Tazobactam: A Retrospective Study

6. Impact of Infection with Extended-Spectrum ß-Lactamase (ESBL)Producing Escherichia coli or Klebisella Species on Outcome and Hospitalization Costs

\section{Medication System Management / Education}

1. Tracking Dispensary Turnaround Time

2. Perceptions and Practices Associated with Reporting Adverse Drug Reactions among Medical and Pharmacy Residents in Quebec

3. Adherence to the Institute for Safe Medication Practices Canada's "Do Not Use" List of Dangerous Abbreviations in Paper and Electronic Medication Orders

4. Opportunities to Enhance Institutional Experiential Education: Placing Students in Pairs Projects

5. Optimization of Workflow and Medication Safety in Unit Dose Dispensing

6. Antimicrobial Medications Incidents and Accidents and Consumption in 2012-2013

Pharmacy Practice

1. How Do Patient, Non-patient and Hospital Pharmacist Stakeholder Perspectives on Clinical Pharmacy Key Performance Indicators for Hospital Pharmacists Compare?

2. Standardization of Pharmacist Attendance at Rounds

3. Standardization of Pharmacists Involvement in Best Possible Medication History and Medication Reconciliation

4. Quality of Nurse-Acquired Best Possible Medication History in an Ambulatory Hemodialysis Centre

5. Assessing Completeness of Best Possible Medication History by Profession

6. Pharmacist Workload on General Medicine and Surgery Units

Therapeutics

1. Evaluation of Interventions to Improve Management of Behavioural and Psychological Symptoms of Dementia in a Residential Care Facility

2. Single versus Dual Antiplatelet Therapy Following Transcatheter Aortic Valve Implantation: A Systemic Review

3. Evaluation of Enoxaparin Pharmacokinetics and Pharmacodynamics to Develop Dose Banding Based on Total Body Weight and Renal Function

4. Adherence to Clinical Practice Guidelines for Antimicrobial Prophylaxis in Surgery

5. Follow-up Point Prevalence Survey of Antimicrobial Use in the Cardiac and Paediatric Critical Care Unit

6. Telepharmacy Support of an Antimicrobial Stewardship Program in a Small Rural Acute Care Hospital

\section{Monday, February 2, 2015 • Lundi 2 février 2015}

1. Evaluation of Inhaled Corticosteroid Prescribing for Chronic Obstructive Pulmonary Disease in Family Medicine Teaching Units

2. Stability of an Epidural Analgesic Admixture Containing Ropivacaine and Epinephrine in Cassette Reservoirs

3. Extended Stability of Sodium Phosphate Solutions in Polyvinylchloride Bags

4. Stability of $100 \mathrm{mg} / \mathrm{mL}$ Ertapenem in Syringes and the Manufacturer's Glass Vial at $4 \mathrm{C}$ and $23 \mathrm{C}$

5. Utilization of Dexmedetomidine in Patients Admitted to a Tertiary Care Medical Surgical Intensive Care Unit

6. Review of the Safety of Disease-Modifying Anti-rheumatic Drug Therapy in Patients with Chronic Kidney Disease

7. Recherche en pratique pharmaceutique : des recettes et astuces en ligne

8. Publications comportant des retombées négatives de l'activité pharmaceutique

9. Comparaison du niveau d'accord à des énoncés sur l'éthique pharmaceutique entre étudiants en pharmacie et pharmaciens hospitaliers canadiens

10. Littérature sur le rôle et les retombées du pharmacien : perceptions d'etudiants canadiens

11. Démarche pour la mise à niveau de soins pharmaceutiques : l'exemple de l'immunisation

12. The Evaluation of Paclitaxel Hypersensitivity Reactions Following the Discontinuation of Prophylactic Pre-Medications

13. Impact of Experiential Learning on the Professional and Personal Development of Undergraduate Pharmacy Students

14. Effectiveness of Extracurricular Journal Clubs on Pharmacy Students' Learning of Evidence-Based Medicine and Critical Appraisal

15. An Environmental Scan of Transition Courses for Pharmacy Students Prior to Advanced Pharmacy Practice Experience Rotations

16. Adherence to Abiraterone among the First Eighty-Six Recipients Following Its Release in Saskatchewan, Canada

17. Development and Implementation of a Peer-Assisted Learning Model to Teach Pharmacy Students in a Clinical Trials Rotation

18. Opportunities to Enhance Institutional Experiential Education: Mutually Beneficial Activities Analysis

19. Doctor of Pharmacy Students Acquire Skills in Curriculum Design and Project Management through Participation in an Education Project with Coaching Support

20. Prevalence of Co-trimoxazole Induced Hyperkalemia in Chronic and Acute Users in a Tertiary Teaching Hospital

21. Planning and Evaluation of a Computerized Prescriber Order Entry Implementation

22. Patient-Perceived Usefulness and Usability of a Smartphone/Online Application in Type 2 Diabetes Self-Management

\section{Tuesday, February 3, 2015 • Mardi 3 février}

1. Pompes intelligentes : évaluation pratique des limites de détection

2. Retrospective Review of Emerging Drug Use in a Mother-Child Center in Quebec

3. Unlicensed and Off-Label Drug Use in a Mother-Child Tertiary Care Hospital

4. Is Pediatric Drug Information the Same for All Children Around the World?

5. Démarche pour la mise à niveau d'un secteur de soins pharmaceutiques : le cas de la pédiatrie

6 Conformité des ordonnances à la règle d'emission des médicaments : étude pilote au sein d'un CHU mère-enfant

7. Audit of the Labelling of Hazardous Drugs in the Canadian Market

8. Tolerability of Darunavir/Ritonavir, Tenofovir/Emtricitabine for Human Immunodeficiency Virus Postexposure Prophylaxis

9. Prophylaxis of Post-traumatic Infectious Endophthalmitis: Probability of Fluoroquinolone Success Using Monte Carlo Simulations

10. Natural Health Product Use in Patients with Rheumatological Conditions 
11. Multidisciplinary Review Process Demonstrates the Need for Early Pharmacist Notification with Treatment Intervention Benefits in Clostridium difficile Infection (CDI)

12. Pharmacist's Perception of the Implementation of Computerized Prescriber Order Entry (CPOE) on Their Practice

13. Anticoagulation and Antiplatelet Patterns in Patients with Atrial Fibrillation Post-percutaneous Coronary Intervention

14. A Pharmacy Practice Residency Program at a Paediatric Quaternary Hospital: Program Review and Evaluation

15. Patient Satisfaction with Chronic HIV Care Provided through an Innovative Pharmacist and Nurse-Managed Clinic or a Multidisciplinary Clinic

16. Use of Therapeutic Drug Monitoring to Improve Paediatric Clinical Pharmacy Service at a Tertiary Hospital

17. Guideline for the Prevention of Breakthrough and Treatment of Refractory Chemotherapy-Induced Nausea and Vomiting in Pediatric Cancer Patients

18. Impact of Pharmacist Interventions on Outpatient Parenteral Antimicrobial Therapy Information Transfer at Hospital Discharge

19. Survey of Healthcare Professionals on the Role of Pharmacists in an Outpatient HIV Clinic Setting

20. Predictors of Bacteremia in the Elderly

21. Determination of Gentamicin Pharmacokinetics in Neonates to Develop Practical Initial Extended-Interval Dosing Recommendations

22. Impact of Length of Stay on the Distribution of Gram Negative Organisms and the Likelihood of Isolating a Resistant Organism in a Canadian Burn Centre

23. Customization and Implementation of a Compounding Software Solution for Safe and Efficient Sterile and Non-sterile Compounding

24. Correlation Between Length of Smoking Cessation Therapy and Rate of Abstinence in Pragmatic Conditions

\section{CSHP 2015}

CSHP 2015 is a quality program that sets out a vision of pharmacy practice excellence in the year 2015. Through this project, CSHP challenges hospital pharmacists to reach measurable targets for 36 objectives grouped under 6 goals, all aimed toward the effective, scientific, and safe use of medications and meaningful contributions to public health. CSHP 2015 applies to inpatients and outpatients, community and hospital pharmacists, and all practice settings. Posters identified with a "CSHP 2015" logo are those judged by the CSHP 2015 Steering Committee to be particularly relevant to one or more of the 36 objectives.

\section{SCPH 2015}

Le projet SCPH 2015 est un programme axé sur la qualité qui propose une vision de l'excellence en pratique pharmaceutique en l'an 2015. Au moyen de ce projet, la SCPH met les pharmaciens d'établissements au défi d'atteindre les cibles mesurables de 36 objectifs répartis entre 6 buts, visant tous l'utilisation efficace, scientifique et sûre des médicaments ainsi que des contributions significatives à la santé publique. Le projet SCPH 2015 s'applique aux patients hospitalisés et externes, aux pharmaciens d'hôpitaux et communautaires, et à tous les milieux de pratique. Les affiches marquées du logo «SCPH 2015 » sont celles que le Comité directeur du projet SCPH 2015 a jugé particulièrement appropriées à l'un ou l'autre des 36 objectifs.

The texts of poster abstracts are published exactly as submitted by the authors and have not undergone any copyediting by the Canadian Journal of Hospital Pharmacy. Le Journal canadien de la pharmacie hospitalière n'a pas soumis le texte des résumés des affiches à une révision linguistique et les publie ici tels que remis par les auteurs.

\section{Acute Kidney Injury with Tobramycin-Impregnated Bone Cement Spacers in Prosthetic Joint Infections: A Controlled Study}

Aeng $E,{ }^{1}$ Shalansky $K,{ }^{2}$ Lau $T,{ }^{2}$ Zalunardo $N,{ }^{2}$ Bowie $W,{ }^{2} L i G,{ }^{2}$

Duncan $C^{2}$

${ }^{1}$ Surrey Memorial Hospital, Surrey, BC

${ }^{2}$ Vancouver General Hospital, Vancouver, BC

Background: Antibiotic-impregnated bone cement spacer (ACS) with tobramycin +/- vancomycin is commonly used in a two-stage replacement of an infected prosthetic joint.

Objectives: We investigated the incidence and risk factors for acute kidney injury (AKI) within 7 days post-operatively after implantation of tobramycin-impregnated bone cement.

Methods: This was a prospective, observational, controlled study of 119 patients from Aug 2011 to Feb 2013. The tobramycin group included 50 consecutive patients who received ACS with tobramycin for the first stage revision of an infected hip or knee arthoplasty. The control group consisted of 69 consecutive patients who had a routine hip arthroplasty revision without ACS. AKI was defined as an increase of $50 \%$ or greater in serum creatinine from baseline within the immediate 7-day post-operative day (POD) period.

Results: The incidence of AKI was higher in the tobramycin group compared to the control group ( $20 \%$ vs. $4.3 \%$, p=0.01). A multivariate analysis adjusting for potential confounders also confirmed the higher incidence of AKI in patients receiving tobramycin ACS (OR 7.2; 95\% CI 1.5-33.5). Mean onset of AKI was on POD 3 in both groups and patients with AKI had longer duration of hospital stay
$(18.6 \pm 13.7$ days vs $8.8 \pm 7.0$ days, $\mathrm{p}<0.0001)$. Other risk factors for AKI were baseline co-morbidity (OR 6.2; 95\% CI 1.3-29.1), and administration of post-operative intravenous vancomycin (OR 5.3; 95\% CI 1.6-17.7) or angiotensin converting enzyme inhibitors/angiotensin II receptor blockers (OR 4.0; 95\% CI 1.2-13.04). Use of pre-manufactured bone cement containing gentamicin was also a risk factor in the tobramycin group (OR 4.5, 95\% CI 1.1-19.3).

Conclusions: The incidence of AKI in infected hip or knee arthroplasties with tobramycin ACS was greater than in routine total hip arthoplasties. Measures to minimize AKI risk in the peri-operative period may reduce the incidence.

\section{Comparison of the Accuracy of 4 Sets of Criteria at Predicting Presence of Pseudomonas aeruginosa in Patients Admitted for Pneumonia}

Sylvestre $A^{1,2}$ Matukas $L,{ }^{1,3}$ Haj $R^{1}$

${ }^{1}$ St. Michael's Hospital, Toronto, ON

${ }^{2}$ Leslie Dan Faculty of Pharmacy, University of Toronto, Toronto, ON

${ }^{3}$ Department of Laboratory Medicine and Pathobiology, University of Toronto, Toronto, ON

Background/Objective: Optimizing the use of antipseudomonal agents requires a balance between providing coverage of likely pathogens and minimizing the risk of bacterial resistance. Criteria have been proposed to identify which patients are at risk for $P$. aeruginosa, but none of these have been validated. We aimed to evaluate the accuracy of different criteria at predicting positive respiratory cultures with $P$. aeruginosa in patients admitted with pneumonia. 
Methods: A retrospective chart review was conducted. Culturepositive patients admitted at a single center for pneumonia between 2009-2013 were included. Four sets of criteria consisting of risk factors for $P$. aeruginosa were applied to a single population. Criteria included decision support from the St. Michael's Hospital pneumonia admission orders (criteria 1; reference criteria), the ATS/IDSA pneumonia guidelines (criteria 2) and two prospective studies: Arancibia et al (criteria 3) and von Baum et al (criteria 4). The primary outcome was the area under the receiver operating curve (AUROC) produced by each set of criteria. Secondary outcomes included the sensitivity and specificity of each criteria and the incidence of each risk factor in the studied population.

Results: Twenty-six cases and sixty controls (with and without positive respiratory cultures for $P$. aeruginosa, respectively) were included. Both groups had similar age, gender and disease severity. The AUROC produced by criteria 2 [0.695 (95\% CI, 0.586-0.789); $\mathrm{p}=0.5576$ ], criteria 3 [0.629 (95\% CI, 0.518-0.730); $\mathrm{p}=0.0716]$ and criteria 4 [0.720 (95\% CI, 0.613-0.811); $\mathrm{p}=0.9803]$ were not statistically sig nificant from the AUROC produced by the reference criteria $[0.721$ (95\% CI, 0.614-0.813)]. While all criteria produced similar specificity, the St. Michael's Hospital reference criteria had the highest sensitivity.

Conclusion: All criteria compared had similar accuracy and low clinical value for predicting positive respiratory cultures with $P$. aeruginosa in patients admitted with pneumonia.

\section{Trends of Antibiotic Use in the Inpatient Acute Care Setting: Is There Evidence of Seasonality?}

Wang $X,{ }^{1}$ Walker $S A N,{ }^{1,2,3}$ Elligsen $M,{ }^{1}$ Nevers $W,{ }^{1}$ Palmay L,

Daneman $N,{ }^{3,4}$ Simor $A{ }^{3,4}$ Leis $J A^{3,4}$

${ }^{1}$ Department of Pharmacy, Sunnybrook Health Sciences Centre, Toronto, $O N$

${ }^{2}$ Leslie Dan Faculty of Pharmacy, University of Toronto, Toronto, ON ${ }^{3}$ Division of Infectious Diseases, Sunnybrook Health Sciences Centre,

Toronto, ON

${ }^{4}$ Faculty of Medicine, University of Toronto, Toronto, $\mathrm{ON}$

Background: Despite the high volume of antibiotic consumption and consequences of antibiotic overuse, little is known about patterns of antibiotic use in hospitalized patients. Understanding patterns of antibiotic use could improve efficiency of antimicrobial stewardship programs by matching interventions to the time of year.

Objectives: To evaluate the presence of seasonality with the use of major classes of antibiotics. To determine the amplitudes, peaks, troughs, and size of any observed seasonal shift in antibiotic use among specific antibiotics that exhibit a seasonal component. To identify whether seasonality of antibiotic use is associated with community versus hospital acquired infections ( $\leq 48$ hours versus $>48$ hours of admission, respectively).

Methods: Hospitalized patients of one acute care teaching hospital who were prescribed systemic antibiotics between December $1^{\text {st }}, 2010$ and November $30^{\text {th }}, 2013$ were included. A time series analysis was employed; the smallest divisible unit was days, with the data presented in equally spaced intervals. A seasonal cycle, defined in the study as 12 months, was assessed using a Poisson regression.

Results: 86,468 clinical encounters were included. Seasonality was evident for azithromycin, ceftriaxone, ciprofloxacin, ceftazidime, and cloxacillin. The magnitude of these individual seasonal relationships varied significantly, with azithromycin exhibiting the strongest seasonal influence (rate ratio $1.5595 \% \mathrm{CI} 1.41-1.70$ ). Antibiotics commonly used to treat community acquired respiratory tract infections (ceftriaxone, levofloxacin, and azithromycin) exhibited peak use during winter months, suggesting a temporal correlation to the annual influenza season with a community influence on hospital antibiotic usage. Monthly counts of antibiotic use were not significantly correlated with monthly C.difficile infection.

Conclusions: Antimicrobial stewardship programs may increase efficiency by understanding antibiotic seasonal patterns of use in order to concentrate efforts based on predictable surges in use. In addition, seasonality may impact antibiotic use independent of stewardship interventions and should be considered when evaluating these initiatives.

\section{Efficacy and Safety of Atazanavir plus Raltegravir Dual Therapy in Treatment-Experienced HIV-1 Infected Patients}

Chen $C,{ }^{1}$ Tseng A, ${ }^{1,2}$ Sterling $S,{ }^{2}$ Salit $I^{1,2}$

${ }^{1}$ University of Toronto, Toronto, $O N$

${ }^{2}$ University Health Network, Toronto, ON

Background: Atazanavir (ATV) plus raltegravir (RAL) is a nontraditional regimen which avoids ritonavir-associated toxicity and interactions and may be effective in patients resistant or intolerant to nucleoside reverse transcriptase inhibitor (NRTIs). Experience in treatment-experienced patients has been promising but data are limited.

Objective: To evaluate the efficacy and safety of twice daily ATV/RAL in treatment-experienced patients.

Methods: A retrospective review of HIV clinic patients between January 1, 2007 and June 31, 2014 was conducted. Patients on concomitant ritonavir or with less than 6 months follow-up were excluded. Efficacy and safety data at 24, 48 weeks and most recent follow-up were compiled.

Results: Sixteen patients were included for analysis: median (range) age 48.5 (36-76) years, 14 (87\%) male, 9 (56\%) Caucasian, 11 (69\%) men who have sex with men. Median duration of HIV infection was 21 (4-27) years, 4 (25\%) had prior AIDS-defining illnesses. Patients received a median of 8.5 (3-14) prior antiretroviral regimens. All patients had pre-existing drug resistance ( $\mathrm{n}=14$ NRTI, 11 non-NRTI, 2 protease inhibitor and 1 raltegravir). Baseline viral load (VL) was undetectable in $9(56 \%)$ patients for a median of 72 (2-130) months prior to starting ATV/RAL; the median VL was 4.39 (1.96-5.2) $\log 10$ copies/mL for 7 (44\%) patients at baseline. Baseline median CD $4^{+}$ was $223(<10-1023)$ cells $/ \mathrm{mm}^{3}$, with median nadir of $104(<10-697)$ cells/ $\mathrm{mm}^{3}$. Reasons for initiating ATV/RAL included adverse reactions/tolerability $(n=9)$, treatment failure $(n=4)$, cost/convenience $(\mathrm{n}=2)$, and drug interactions $(\mathrm{n}=1)$. Median duration of follow-up was 23.9 (6.1-51.9) months. Fourteen (87.5\%) patients achieved and maintained virologic suppression. Two patients experienced virologic rebound due to treatment interruption/ nonadherence without development of new resistance mutations. The median increase in $\mathrm{CD}^{+}$count was 143 cells $/ \mathrm{mm}^{3}$. No patients experienced serious medication-related adverse events.

Conclusion: Atazanavir plus raltegravir is an effective, durable and safe regimen in treatment-experienced patients. 


\section{Outcomes in Documented Pseudomonas aeruginosa Bacteremia Treated with Intermittent Infusion Intravenous Ceftazidime, Meropenem, and Piperacillin/Tazobactam: A Retrospective Study \\ Kwee $F^{1}$ Walker $S A N,{ }^{1,2,3}$ Elligsen $M,{ }^{1}$ Palmay $L,{ }^{1}$ Simor $A,{ }^{3,4}$ \\ Daneman $N^{3,4}$ \\ ${ }^{1}$ Department of Pharmacy, Sunnybrook Health Sciences Centre, \\ Toronto, ON \\ ${ }^{2}$ Leslie Dan Faculty of Pharmacy, University of Toronto, Toronto, ON \\ ${ }^{3}$ Department of Microbiology and Division of Infectious Diseases, \\ Sunnybrook Health Sciences Centre, Toronto, ON \\ ${ }^{4}$ Faculty of Medicine, University of Toronto, Toronto, $\mathrm{ON}$}

Background: P. aeruginosa is one of the leading causes of nosocomial Gram-negative bloodstream infections and is particularly difficult to treat because of its multiple resistance mechanisms in combination with the lack of novel anti-pseudomonal antibiotics. Despite the knowledge of time dependent killing with ß-lactam antibiotics, most hospitals currently administer ß-lactam antibiotics by intermittent rather than extended infusions.

Objectives: To determine clinical outcomes, microbiological outcomes, total hospital costs and infection-related costs in patients with $P$. aeruginosa bacteremia receiving intermittent intravenous anti-pseudomonal $ß$-lactam antibiotics in a tertiary care institution.

Methods: This retrospective descriptive study collected data from patients admitted between March 1, 2005 and March 31, 2013 with Pseudomonas aeruginosa bacteremia who received at least 72 hours of ceftazidime, meropenem, or piperacillin/tazobactam to determine outcomes and costs.

Results: A total of 103 patients were included in the analysis. Clinical cure was seen in seventy-nine $(77 \%)$ patients, with bacterial eradication achieved in $87 \%$ of the evaluable patients. Twenty-eight patients (27\%) died within 30 days of therapy. The median total hospital stay cost and infection-related hospital stay cost for hospitalized patients with $P$. aeruginosa bacteremia were $\$ 121,718(\mathrm{Cdn})$ and $\$ 29,697$ $(\mathrm{Cdn})$, respectively.

Conclusions: $P$. aeruginosa bacteremia is a significant nosocomial infection that continues to cause considerable mortality and cost to the healthcare system. To the best of our knowledge, no existing studies have identified total and infection related hospital costs for patients with Pseudomonas aeruginosa bacteremia treated with intermittent infusion anti-pseudomonal ß-lactams. This study may provide important baseline data to assess the impact of implementation of continuous infusion beta-lactam strategies in hospitalized patients.

\section{Impact of Infection with Extended-Spectrum B-Lactamase (ESBL)-Producing Escherichia coli or Klebsiella Species on Outcome and Hospitalization Costs}

Maslikowska JA, ${ }^{1}$ Walker SAN, ${ }^{1,2,3}$ Elligsen $M,{ }^{1}$ Mittmann $N, 4,5$ Palmay $L,{ }^{1}$ Daneman $N,{ }^{3,6,7}$ Simor $A^{3,6,7}$

${ }^{1}$ Department of Pharmacy, Sunnybrook Health Sciences Centre, Toronto, ON

${ }^{2}$ Leslie Dan Faculty of Pharmacy, University of Toronto, Toronto, ON ${ }^{3}$ Division of Infectious Diseases, Sunnybrook Health Sciences Centre, Toronto, $O N$

${ }^{4}$ HOPE Research Centre, Sunnybrook Health Sciences Centre, Toronto, ON ${ }^{5}$ Department of Pharmacology, University of Toronto, Toronto, $O N$

${ }^{6}$ Faculty of Medicine, University of Toronto, Toronto, $O N$

${ }^{7}$ Sunnybrook Research Institute, Toronto, ON
Background: Extended spectrum ß-lactamase (ESBL)-producing bacteria are important sources of infection; however Canadian data elucidating the impact of ESBL-associated infection are limited.

Objectives: To determine whether patients who are infected with ESBL-producing E. coli or Klebsiella spp. (ESBL-EcKs) exhibit differences in (i) clinical outcome; (ii) microbiological outcome; (iii) mortality; and/or (iv) hospital resource use in comparison to patients infected with non-ESBL-producing strains.

Methods: We conducted a retrospective case-control study of patients admitted to hospital between June 2010 and April 2013. Seventy-five case patients infected with ESBL-EcKs were matched one-to-one with controls infected with non-ESBL-EcKs. Patient-level cost data were provided by the institution's Business Office. Clinical data were collected using the Antimicrobial Stewardship database, electronic patient records, and paper charts.

Results: Patients had a mean age of 68 years, $47 \%$ of whom were male. Median infection-related hospitalization costs per patient were greater for cases than controls $(\mathrm{CN} \$ 10,507$ vs. $\mathrm{CN} \$ 7,882$; median difference, $\mathrm{CN} \$ 3,416 ; p=0.04)$. The primary driver of increased costs was prolonged infection-related hospital length of stay (IR-LOS) (8 vs. 6 days; $p=0.02)$. Cases were more likely to experience clinical failure ( $25 \%$ vs. $11 \%$; $p=0.03)$, with a higher rate of all-cause mortality $(17 \%$ vs. $5 \% ; p=0.04)$. Less than half of case patients were prescribed appropriate empiric antimicrobial therapy, while controls received adequate initial treatment in nearly all circumstances ( $48 \%$ vs. $96 \%$; $p<0.01)$.

Conclusions: Our results suggest that patients with infection caused by ESBL-EcKs are at increased risk for clinical failure and mortality, and that the additional cost to the Canadian healthcare system to treat one patient with an ESBL-positive infection is a median of $\mathrm{CN} \$ 3,416$ more due to prolonged IR-LOS. Since our study only evaluated infected patients and controls, unmeasured confounding factors that may influence both the likelihood of acquiring ESBL-EcKs and mortality may exist (e.g., comorbidities, severity of illness, LOS).

\section{Tracking Dispensary Turnaround Time}

Tilli T, ${ }^{1,2}$ Garland J, ${ }^{1}$ Davies $P^{1}$ Lail $S^{1}$

${ }^{1}$ St. Michael's Hospital, Toronto, ON

${ }^{2}$ Leslie Dan Faculty of Pharmacy, University of Toronto, Toronto, ON

Background: Delays in medication turnaround time (TAT) can result in harm to patients. Dispensary TAT is defined as the time elapsed from the start to the end of the medication dispensing process.

Description: In-patient interim dose dispensing TAT was analyzed at a teaching hospital. Medications were ordered in a Computerized Physician Order Entry environment with 24 hour cart exchange and a robotic dispensing system. Dispensary TAT began at the point of medication order validation by the pharmacist, and concluded once medications left the dispensary via porter or pneumatic tube. Time spent in each step of the dispensing process was measured to identify potential areas of improvement.

Action: The in-patient pharmacy dispensary workflow was mapped and the time for each step in dispensing was documented for 651 medication orders. The steps were: 1) medication label printed, 2) medication dispensed, 3) medication checked, 4) medication left the dispensary. The medication name, patient identification number, and urgency were captured for each prescription. The data was analyzed to determine the average dispensary TAT and the time taken to complete each step.

Evaluation: The average dispensary TAT for all prescriptions was 56 minutes; this was divided into an average of 14 minutes to dispense 
and check a medication, and an average of 42 minutes for a medication to leave the dispensary. Stat medications labeled as a one-time dose, due within the hour, or new start, had an average dispensary TAT of 35, 44, and 56 minutes, respectively. Non-stat medications had an average dispensary TAT of 61 minutes.

Implications: Stat medications must be clearly identified and prioritized for timely delivery. The evaluation of dispensary TAT revealed relatively quick dispensing and checking, but a relatively prolonged time for medications to leave the dispensary. As a patient safety initiative, strategies to improve dispensary TAT should target medication delivery.

\section{Perceptions and Practices Associated with Reporting Adverse Drug Reactions among Medical and Pharmacy Residents in Quebec \\ Cerruti $L,{ }^{1}$ Lebel D, ${ }^{1}$ Bussières $J F^{1,2}$ \\ ${ }^{1}$ Pharmacy Department and Pharmacy Practice Research Unit, CHU Sainte-Justine, Montéal, QC \\ ${ }^{2}$ Faculty of Pharmacy, Université de Montréal, Montréal, QC}

Background: The success of drug safety surveillance relies on an efficient pharmacovigilance system, spontaneous reporting of adverse drug reactions (ADR) by healthcare professionals to regulatory authorities. Residents should play a role in the detection and reporting of serious, unexpected and unusual ADR.

Objective: The aim of this study was to compare perceptions and practices associated with reporting ADR among medical and pharmacy residents.

Methods: A prospective descriptive study was conducted in March/April 2014 using a web questionnaire with 16 items and 5 sections: demographics, pharmacovigilance training and practices, obstacles to reporting ADR and measures to improve ADR reporting. The selfadministered questionnaire was sent by email to Quebec pediatric medical residents and pharmacy residents.

Results: Thirty-six medical residents (response rate 36/151,24\%) and 34 pharmacy residents $(34 / 67,51 \%)$ completed the survey. Aside undergraduate pharmacy curriculum, only 2 residents had completed additional pharmacovigilance training. Unlike medical residents, pharmacy residents believed that they were well-prepared to report and analyze an ADR and that pharmacovigilance was well-covered in their curriculum (24/34,71\% versus 10/35,29\%). During their residency, the majority of respondents were exposed to more than 100 patients $(63 / 70,90 \%)$ and to more than 4 serious/unexpected ADR (51/70,73\%). 7/36 medical residents and 33/34 pharmacy residents reported at least one or more serious or unexpected ADR to the regulatory authority. While most important obstacles to reporting ADR were different between both groups, lack of experience was common. Finally, regarding measures to improve $\mathrm{ADR}$ reporting, respondents saw decentralized pharmacists in patient care wards as a key success factor as well as onsite designed pharmacovigilance pharmacy coordinator.

Conclusions: This study revealed a lack of satisfaction in pharmacovigilance training in medicine curriculum but a willingness of both residents to contribute to drug safety surveillance. A better understanding of perceptions and obstacles to reporting ADR can help identify measures to improve ADR reporting.

\section{Adherence to the Institute for Safe Medication Practices Canada's "Do Not Use" List of Dangerous Abbreviations in Paper and Electronic Medication Orders}

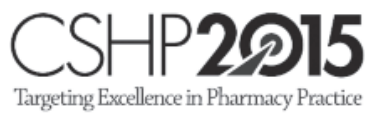

Cheung S, ${ }^{1}$ Hoi S, ${ }^{1}$ Fernandes $O,{ }^{1,2}$ Huh J, ${ }^{2}$ Kynicos $S,{ }^{2}$ Murphy $L,{ }^{2}$ Lowe $D^{2}$

${ }^{1}$ Leslie Dan Faculty of Pharmacy, University of Toronto, Toronto, ON ${ }^{2}$ Department of Pharmacy Services, University Health Network, Toronto, ON

Background: Dangerous abbreviations on the Institute for Safe Medication Practices (ISMP) Canada's "Do Not Use" list have resulted in harmful medication errors. Data comparing the rates of dangerous abbreviation use in paper and electronic medication orders are limited.

Objectives: To compare the rates of dangerous abbreviation use, defined by ISMP Canada's "Do Not Use" list, in paper and electronic medication orders. Secondary objectives include determining the proportion of patients at risk of medication errors due to dangerous abbreviations and those most commonly used.

Methods: We conducted 1-day cross-sectional audits of medication orders using a convenience sample of 5 patients per nursing unit at a 6-site teaching hospital organization in December 2013 and January 2014. Proportions of paper and electronic medication orders containing dangerous abbreviation(s) were compared using a Chi-squared test. Proportion of patients with at least 1 medication order containing dangerous abbreviation(s) and the top 5 dangerous abbreviations used were described.

Results: Overall, 258 charts were reviewed, with 3 excluded as patients were discharged before electronic orders could be reviewed. The proportions of paper and electronic medication orders containing dangerous abbreviation(s) were 172/714 (24.1\%) and 9/2207 (0.4\%), respectively $(\mathrm{p}<0.001)$. Overall, 76 out of $255(29.8 \%)$ patients had at least 1 medication order containing dangerous abbreviation(s). Those most commonly used were " $\mathrm{D} / \mathrm{C}$ ", drug name abbreviations, "OD", "U", and "cc".

Conclusions: Electronic medication orders have significantly lower rates of dangerous abbreviation use than paper medication orders. Almost one-third of patients are at risk of harmful medication errors from dangerous abbreviation use.

\section{Opportunities to Enhance Institutional Experiential Education: Placing Students in Pairs Project}

Yu F, Luong W, Legal M, Loewen P

University of British Columbia, Vancouver, BC

Background: Our faculty recently conducted a province-wide stakeholder engagement project to identify strategies to better support learners and preceptors who participate in experiential placements at hospital sites. With program expansion there is an increased need for high quality experiential placements. A key project suggestion was to promote the adoption of non-1:1 learner-preceptor models and that pairs of learners should be the default model for entry to practice learners.

Description: This study aimed to gain a deeper understanding of the practical use of the paired model in order to identify and develop ways to better support local preceptors who consider adopting non-1:1 models. 
Action: The perspectives of learners and preceptors who recently participated in a paired rotation were gathered through one on one semi-structured interviews. The interviews were recorded and the resulting field notes were analyzed using qualitative methods and iterative coding to identify major themes.

Evaluation: A total of 17 preceptors and 9 learners participated. General perspectives on the paired model were quite positive. Learners and preceptors both agreed that paired learning promoted peer-assisted learning. Being able to "bounce ideas off of each other" allowed students to feel more confident, independent, and less-intimidated. One area of concern was that differences in ability, learning styles or personalities can present as a challenge. Tips and suggestions on how to minimize learner conflict, optimize time management, and approach learner evaluations were identified.

Implications: This work provides insight into the perspectives of local preceptors and learners regarding the paired model. Compiling their tips and suggestions into educational materials for preceptors may assist them in making the transition to novel learner-preceptor models.

\section{Optimization of Workflow and Medication Safety in Unit Dose Dispensing

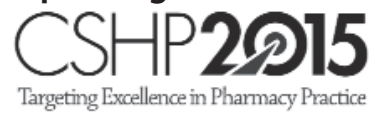

Facca N, DiCarlo A, Eddy S, Hasan R, Spence Haffner R, Jansen S

London Health Sciences Centre, London, ON

Background: A need was identified to increase patient safety and efficiency in the inpatient unit dose area of a pharmacy within a major, acute care, tertiary, academic hospital. Changes were desired before the transition of pharmacy services to $24 / 7$ and computerized provider order entry implementation.

Description: Redesigning the workflow and workspace was thought to reduce interruptions, which in turn would decrease medication filling errors and increase patient safety. Reducing time to fill medication carts would increase efficiency and effectiveness.

Action: A thorough analysis (using a LEAN quality improvement approach) of the processes, workspace and workflow was completed. The volume of activity was analyzed to determine optimal staffing levels. The schedule was revised to align shifts with peak activity. Reducing non-essential, non-value added work was desired. An event was held to sort, set in order, shine, standardize and sustain ("5S") the proposed future state. "Plan-Do-Check-Act" cycles were completed during implementation to refine processes.

Evaluation: Direct observation of work, timing of medication cart filling, counts of medication returns, counts of adverse event reports and discussions with staff were done to assess current and future state. One month after implementation, the number of interruptions during medication cart filling had decreased by $43 \%$. There was positive staff feedback on the space redesign. Fewer adverse errors were reported and a decreased amount of time was noted in filling the medication carts. Independent double checking of medication carts increased by $10 \%$ (this value has continued to improve since implementation). Ninety-five percent of medication carts were filled within the new target time. There was no change in the number of steps required to fill each medication cart.

Implications: A quality improvement approach helped to identify opportunities for increased efficiency and safety within the pharmacy environment. Positive results were obtained after thorough analysis of workflow and workspace redesign.

\section{Antimicrobial Medications Incidents and Accidents and Consumption in 2012-2013}

Bérard C, ${ }^{1}$ Lebel D, ${ }^{1}$ Bussières $J F^{1,2}$

${ }^{1}$ Pharmacy Department and Pharmacy Practice Research Unit, CHU

Sainte-Justine, Montréal, QC

${ }^{2}$ Faculty of Pharmacy, Université de Montréal, Montréal, QC

Background: The optimisation of antimicrobial use includes prevention, risk management systems and consumption data analysis. Currently, defined daily dose (DDD) and days of therapy (DOT) are used to monitor antimicrobial drug consumption. In 2010, HealthCanada implemented a federal program to improve medication incident and accidents (I/A) reporting. In Quebec, according to the Ministère de la Santé et des Services Sociaux (MSSS), the reporting of medication I/A occurring in any health care situation has been mandatory since 2002. These I/As are notified in a national data register.

Objectives: The objective was to quantify antimicrobial-associated I/A rates and to compare them with antimicrobial drug consumptions in a university mother-child hospital.

Methodology: Antimicrobial drug consumption data was extracted from pharmaceutical software (GESPHARx8®) for all hospitalized patients who received systemic antimicrobials between April $1^{\text {st }}, 2012$ and March $31^{\text {st }}, 2013$. I/As were reported using the MSSS approved written formulary (AH-223) and were paired with associated antimicrobial drug consumption data, using two new approaches: I/As/DDD and I/As/DOT ratios.

Results: The following table shows I/As and drug consumption data for antimicrobial agents in our center. Ten antimicrobial agents $(29 \%$ of antimicrobial agents) associated with the highest number of I/A reports accounted for $76 \%$ of the DDD, $70 \%$ of DOT and $58 \%$ of I/As reports.

Incidents and accidents and consumption data for antimicrobial agents

\begin{tabular}{|c|c|c|c|c|c|}
\hline Antimicrobial agent & $\begin{array}{c}\text { Number } \\
\text { of I/A }\end{array}$ & $\begin{array}{l}\text { Number } \\
\text { of DDD }\end{array}$ & $\begin{array}{l}\text { Number } \\
\text { of DOT }\end{array}$ & $\begin{array}{c}\text { Number of } \\
\text { I/A/10000 } \\
\text { DDD }\end{array}$ & $\begin{array}{c}\text { Number of } \\
\text { I/A / } 10000 \\
\text { DOT }\end{array}$ \\
\hline Ampicillin & 34 & 9199 & 9309 & 37 & 37 \\
\hline Vancomycin & 31 & 3342 & 6102 & 93 & 51 \\
\hline Gentamycin & 27 & 2879 & 8061 & 94 & 33 \\
\hline Tobramycin & 18 & 3835 & 5323 & 47 & 34 \\
\hline Amoxicillin & 15 & 3827 & 4143 & 39 & 36 \\
\hline $\begin{array}{l}\text { Piperacillin + } \\
\text { tazobactam }\end{array}$ & 15 & 2501 & 5440 & 60 & 28 \\
\hline Cefotaxime & 15 & 3149 & 4643 & 48 & 32 \\
\hline Cefazolin & 14 & 3140 & 4652 & 45 & 30 \\
\hline Cloxacilline & 14 & 2526 & 1854 & 55 & 76 \\
\hline Clindamycin & 12 & 2223 & 3024 & 54 & 40 \\
\hline Acyclovir & 8 & 397 & 2683 & 202 & 30 \\
\hline Metronidazole & 7 & 1390 & 2585 & 50 & 27 \\
\hline Ceftriaxone & 6 & 612 & 1244 & 98 & 48 \\
\hline Meropenem & 6 & 1755 & 1864 & 34 & 32 \\
\hline $\begin{array}{l}\text { Amoxicillin + } \\
\text { clavulanic acid }\end{array}$ & 5 & 1649 & 1375 & 30 & 36 \\
\hline Linezolid & 5 & 133 & 189 & 376 & 265 \\
\hline Erythromycin & 4 & 497 & 1002 & 80 & 40 \\
\hline Fluconazole & 4 & 2558 & 5230 & 16 & 8 \\
\hline $\begin{array}{l}\text { Ticarcillin + } \\
\text { clavulanic acid }\end{array}$ & 4 & 1176 & 2509 & 34 & 16 \\
\hline Doxycyclin & 3 & 84 & 198 & 357 & 152 \\
\hline Cefoxitine & 3 & 329 & 713 & 91 & 42 \\
\hline Cephalexin & 2 & 748 & 1165 & 27 & 17 \\
\hline Ceftazidime & 2 & 1873 & 1987 & 11 & 10 \\
\hline Rifampicin & 2 & 190 & 306 & 105 & 65 \\
\hline Imipenem+cilastatine & 1 & 54 & 78 & 185 & 128 \\
\hline
\end{tabular}




\begin{tabular}{llrrrc} 
& & & \multicolumn{2}{c}{ continued from page 69 } \\
\hline Cefprozil & 1 & 104 & 218 & 96 & 46 \\
\hline $\begin{array}{l}\text { Amphotericin B } \\
\text { (liposomal) }\end{array}$ & 1 & 278 & 494 & 36 & 20 \\
\hline Ganciclovir & 1 & 185 & 460 & 54 & 22 \\
\hline Azithromycin & 1 & 1084 & 999 & 9 & 10 \\
\hline Levofloxacin & 1 & 568 & 702 & 18 & 14 \\
\hline Voriconazole & 1 & 414 & 483 & 24 & 21 \\
\hline Caspofungin & 1 & 1198 & 1683 & 8 & 6 \\
\hline Colistimethate & 1 & 412 & 501 & 24 & 20 \\
\hline Clarithromycine & 1 & 791 & 1075 & 13 & 9 \\
\hline Ciprofloxacine & 1 & 2257 & 2097 & 4 & 5 \\
\hline Total & 315 & 48158 & 75082 & $\begin{array}{c}\text { Non } \\
\text { applicable }\end{array}$ & $\begin{array}{c}\text { Non } \\
\text { applicable }\end{array}$ \\
\hline Legend: defined daily dose (DDD), days of therapy (DOT), incidents and accidents (I/A)
\end{tabular}

Conclusion: Ten antimicrobial agents were associated with $58 \%$ of all I/A reports and were also commonly prescribed in our center (according to DDD and DOT). As part of antimicrobial stewardship and risks management program, it can be useful to compare I/A reports and consumption data to focus on antimicrobial agents that should be closely evaluated.

\section{How Do Patient, Non-patient and Hospital Pharmacist Stakeholder Perspectives on Clinical Pharmacy Key Performance Indicators for Hospital Pharmacists Compare?}

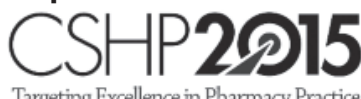

Mourao D, ${ }^{1}$ Raymond $C,{ }^{1,2}$ Slobodan $J{ }^{3}$ Gorman $S K,{ }^{4}$ Toombs $K,{ }^{5}$

Doucette D, ${ }^{6}$ Nghiem $C L,{ }^{2}$ Law $V^{1}$ De Angelis $C,{ }^{2,7} M c$ Gillicuddy $P^{1,8}$

Nichol $K,{ }^{1,9,10}$ Bell B, ${ }^{11,12}$ Fernandes $O^{1,2}$

${ }^{1}$ University Health Network, Toronto, ON

${ }^{2}$ Leslie Dan Faculty of Pharmacy, University of Toronto, Toronto, $O N$

${ }^{3}$ Alberta Health Services, Red Deer, $A B$

${ }^{4}$ Interior Health Authority, Kelowna, BC

${ }^{5}$ Capital District Health Authority, Halifax, NS

${ }^{6}$ Horizon Health Network, Moncton, NB

${ }^{7}$ Sunnybrook Odette Cancer Centre, Toronto, ON

${ }^{8}$ Wightman-Berris Academy, University of Toronto, Toronto, ON

${ }^{9}$ Dalla Lana School of Public Health, University of Toronto, Toronto, ON

${ }^{10}$ Lawrence S Bloomberg Faculty of Nursing, University of Toronto, Toronto, $O N$

${ }^{11}$ Mount Sinai Hospital, Toronto, ON

${ }^{12}$ Institute of Health Policy, Management and Evaluation, University of Toronto, Toronto, $\mathrm{ON}$

Background: The systematic, evidence-informed consensus process of developing the national clinical pharmacy key performance indicators (cpKPI) for hospital pharmacists to date has not involved stakeholder feedback.

Description: To systematically gather national stakeholder feedback on the cpKPI and compare quantitative data among stakeholder subgroups to refine and optimize the cpKPI.

Action: A focus group or individual interview was used to gather stakeholder feedback on the consensus cpKPI. The focus group/interview consisted of an informative presentation, a questionnaire and qualitative discussion. A stakeholder was defined as: (i) a person or leader who interacts with an inpatient hospital pharmacist on a regular basis; (ii) a person involved in the measurement of quality/performance indicators; or (iii) a person who is a recipient of direct patient care from an inpatient hospital pharmacist. Stakeholders included hospital pharmacists, physicians, nurses, allied health professionals, hospital administrators, non-hospital pharmacists and patients. Quantitative data was analyzed using descriptive statistics.

Evaluation: Feedback was gathered from 126 stakeholders ( 79 hospital pharmacists, 30 non-patients and 17 patients). Overall, 91\% (107/117) of participants agreed or strongly agreed that measuring these cpKPI for hospital pharmacists will be useful in advancing clinical pharmacy practice to improve the quality of patient care. The highest priority cpKPI varied among the subgroups. Drug therapy problems resolved was the highest priority cpKPI for hospital pharmacists, whereas admission medication reconciliation and patient education at discharge were the highest priority for non-patients and patients respectively. The cpKPI statements that were least understood by participants were development and implementation of a pharmaceutical care plan $(68 \%, 81 / 125)$ and bundled patient care interventions $(70 \%, 84 / 125)$.

Implications: Stakeholders felt that measuring these consensus cpKPIs is important, although there is some variation among stakeholder subgroups as to the most important and useful cpKPI. These perspectives will serve to optimize the consensus cpKPI and prioritize implementation.

\section{Standardization of Pharmacist Attendance at Rounds}

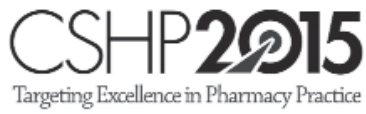

Proceviat J, ${ }^{1}$ Dewhurst $N F^{1,2}$ Tom $E^{1}$

${ }^{1}$ St. Michael's Hospital, Toronto, ON

${ }^{2}$ Leslie Dan Faculty of Pharmacy, Toronto, ON

Background: Evidence supports the active participation of pharmacists in medical rounds as an activity that improves patient outcomes. Since numerous types of medical rounds are available on patient care units, selecting relevant ones to attend while ensuring other clinical duties are fulfilled has become challenging for a large group of pharmacists in a variety of practice settings with competing priorities.

Description: Due to the large variation in types of rounds available on different patient care units, a standard approach towards the prioritization of pharmacist attendance at rounds was required.

Action: A survey was developed and validated by a group of clinical pharmacists from a variety of practice areas to gather information on current state of pharmacist involvement in various rounds available. Data was collected detailing types of rounds available, frequency of attendance, and pharmacist perceived value of attendance. The results were used to develop a policy on pharmacist attendance at rounds.

Evaluation: Responses were received from 31/33 (94\%) clinical pharmacists practicing on inpatient units. Rounds were routinely attended by $31 / 33$ pharmacists. Twelve different types of rounds were attended by pharmacists, with the top three being multidisciplinary, bedside, and bullet (discharge) rounds. These three were ranked as "high" value added rounds, where drug therapy problems (DTPs) were identified and resolved by $79 \%(22 / 28)$ of pharmacists. High value added rounds were attended daily by $58 \%(11 / 19)$ of pharmacists. DTPs were resolved by $53 \%(10 / 19)$ of pharmacists at multidisciplinary rounds compared to $73 \%(8 / 11)$ at bedside rounds and 50\% (4/8) at bullet rounds.

Implications: Multidisciplinary, bedside and bullet (discharge) rounds were identified to be value added and assist to identify and resolve DTPs. These rounds are prioritized for attendance by a pharmacist, regardless of patient care area, allowing for standardization of pharmacist practice. 


\section{Standardization of Pharmacists Involvement in Best Possible Medication History and Medication Reconciliation}

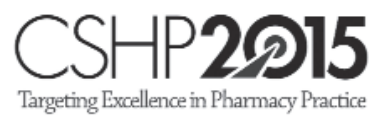

Dewhurst $N F^{1,2}$ Proceviat J, ${ }^{1}$ Tom $E^{1}$

${ }^{1}$ St.Michael's Hospital, Toronto, ON

${ }^{2}$ Leslie Dan Faculty of Pharmacy, Toronto, ON

Background: Medication reconciliation is an important safety initiative, but variation exists amongst pharmacists in selection of which patients are prioritized. In order to balance performance of medication reconciliation and other clinical duties, standard criteria for prioritization was necessary.

Description: In order to minimize variation amongst pharmacists in patient selection, the process of standardizing practice for best possible medication history $(\mathrm{BPMH})$ initiation and medication reconciliation was required to allow all pharmacists to apply a consistent approach.

Action: Data was collected to enable description of demographic and medication related characteristics of admitted inpatients. Characteristics were analysed to determine the optimal combination to capture at least half of all admissions, a cut-off deemed by pharmacists as a reasonable amount to allow time for other duties. The identified characteristics were used as the basis for pharmacist selected patient prioritization. Validation of use of this criterion occurred to determine the feasibility of use in practice.

Evaluation: Two medical and 2 surgical units were audited over a 7-day period. 126 patient charts were reviewed, with 106 (84\%) having a documented BPMH. Pharmacists initiated 51 (48\%) BPMHs. Of these, $36(71 \%)$ patients were aged $\geq 65$. Prior to admission, $36(71 \%)$ patients were on high risk medications and $42(82 \%)$ patients were on $\geq 5$ medications. These characteristics were tried in 12 permutations to identify criteria that would capture $50 \%$ of all admissions. The criterion of high risk medications was expected to be present in $52 \%$ of all audited patients, and therefore selected as criteria for pharmacist prioritization of BPMH initiation.

Implications: Prioritizing patients on high risk medications was identified as the best criteria to standardize pharmacist initiated BPMH. Standardization enables the discipline to set minimum criteria for when BPMHs and medication reconciliation will be provided by pharmacists to enable a balance of clinical duties.

\section{Quality of Nurse-Acquired Best Possible Medication History in an Ambulatory Hemodialysis Centre}

Zhao L, Chong S, Newman P

Kingston General Hospital, Kingston, ON

Background: Hemodialysis (HD) patients are vulnerable to adverse drug events due to complex medication regimens, frequent dose changes, and poor adherence. An accurate best possible medication history (BPMH), obtained during medication reconciliation, can be utilized to identify and resolve drug-related problems. Due to resource limitations, the BPMH is often obtained by nurses in HD centres.

Objectives: The primary objective was to compare the accuracy of $\mathrm{BPMHs}$ obtained by nurses to pharmacists for HD outpatients at our hospital. Secondary objectives include analysis of BPMH discrepancies, discrepancy severities, identification of process improvements, and evaluation for educational opportunities.
Methods: A sample of HD outpatients was randomly selected to be interviewed independently by both a nurse and a pharmacist in a crossover design. BPMHs were manually documented on an existing medication list for each patient and compared following both sets of interviews. Discrepancies between nurse-acquired and pharmacistacquired BPMHs were analyzed.

Results: Fifty-nine patients were included in the study; 2 pharmacists and 27 nurses obtained BPMHs. Nurses and pharmacists agreed on 678 of the total 821 medication regimens reviewed (agreement rate $=$ $82.6 \%)$. Of the 161 discrepancies identified, the most common type was incorrect frequency $(31.7 \%)$ followed by incorrect dose $(31.1 \%)$. The majority $(75.3 \%)$ of the discrepancies were judged to have no potential to cause harm. However, $24.7 \%$ of the discrepancies had the potential to cause moderate to severe discomfort or clinical deterioration. The top three drug classes involved in these potentially harmful discrepancies were anti-diabetics, analgesics, and mineral supplements.

Conclusion: Nurses at the hospital HD centre were able to obtain $\mathrm{BPMHs}$ with similar accuracy as pharmacists. Continued training on patient interview and $\mathrm{BPMH}$ documentation is required to further improve quality of nurse-acquired BPMHs. Education on high risk drug classes is necessary to reduce number of potentially harmful discrepancies.

\section{Assessing Completeness of Best Possible Medication History by Profession

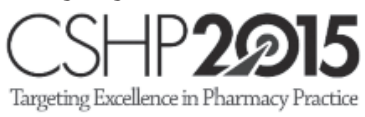

Sweet K, Sellinger D, Dimond J

Pasqua Hospital, Regina Qu'Appelle Health Region, Regina, SK

Background: A prior study illustrated the increased accuracy of the Best Possible Medication History (BPMH) when performed by trained pharmacy technicians. This study examines continued effectiveness of pharmacy technicians across a 3 month trial.

Description: The completion of a BPMH is required for all admitted patients. An accurate BPMH minimizes the potential for errors during medication reconciliation. The responsibility of gathering BPMH is not delegated to one particular profession, though the task is typically performed by a Registered Nurse (RN) or a Licensed Practical Nurse (LPN). Initially, it was unknown which profession would be best suited to gathering $\mathrm{BPMH}$.

Action: A prior study indicated that allowing pharmacy technicians to collect BPMH increased the overall accuracy of the information. Subsequently, a pilot project was implemented in the Emergency Department. Trained pharmacy technicians gathered all BPMH information including allergies, prescriptions, herbals, and over-the-counter (OTC) medications. Other professions only gathered BPMH when the Pharmacy Department was closed.

Evaluation: An auditing form was developed to perform a retrospective chart review of 941 patients who visited the Emergency Department during a 3 month period. The auditing form was designed to determine the completeness of BPMH, and quantify the use of dangerous abbreviations. The results of this evaluation show that, when compared to RNs and LPNs, pharmacy technicians had higher rates of completed $\mathrm{BPMH}$ information, including a larger number of herbals and OTC medications identified. Pharmacy technicians also have significantly lower rates of dangerous abbreviations present on BPMH forms. 
Implications: The accuracy and completeness of BPMH information can be increased by delegating the duty to pharmacy technicians. As pharmacy technicians become licensed, their expanding scope of practice could include the gathering of BPMH. An accurate BPMH will allow physicians and pharmacists to make more informed clinical decisions, thereby improving patient care and safety.

\section{Pharmacist Workload on General Medicine and Surgery Units}

Peragine $C,{ }^{1,2}$ DeCaria $K,{ }^{1}$ Marchesano $R,{ }^{1}$ Appel $G,{ }^{1}$ Barnes $M,{ }^{1}$ Chan $K,{ }^{1}$ Compani $S,{ }^{1}$ Do J, ${ }^{1}$ Harper J, ${ }^{1}$ Kim J, ${ }^{1}$ Ko E, ${ }^{1}$ Le $M,{ }^{1}$ Lee J, ${ }^{1}$ Lo $C,{ }^{1}$ Natanson $R,{ }^{1}$ Pradhan $R,{ }^{1}$ Redekop $L,{ }^{1}$ Rzyczniak $G,{ }^{1}$ Tsang $L,{ }^{1}$ Vella $D,{ }^{1}$ Vyas $A,{ }^{1}$ Carating $H,{ }^{1}$ Walker SE ${ }^{1,2}$

${ }^{1}$ Department of Pharmacy, Sunnybrook Health Sciences Centre, Toronto, ON

${ }^{2}$ Leslie Dan Faculty of Pharmacy, University of Toronto, Toronto, ON

Background: Our institution chose to change a 36-bed surgical oncology/ general surgery unit to a mixed unit containing 24 surgical oncology/general surgery beds and 12 short-stay (SS) general internal medicine (GIM) beds.

Objective: Determine the difference in pharmacist workload as a function of service and length of stay (LOS).

Methods: A data collection form was developed to capture specific pharmacist tasks completed on each patient. Tasks included medication history and reconciliation, dose clarifications, drug related problems and discharge counseling/tasks. For a period of 4 weeks pharmacists recorded the time to complete every task associated with each patient to determine total time/task as well as the total pharmacist time/patient (PTPP). ANOVA was used to evaluate workload factors, differences between services and calculate confidence intervals around mean times.

Results: Data on 550 patients were obtained. The majority of patients were either GIM patients $(n=191)$ or surgery patients $(n=159)$. Pharmacist time per GIM patient averaged 40.8 minutes and the time per surgery patient averaged 28.7 minutes. The LOS for these patients averaged 9.3 and 8.1 days, respectively. When focusing only on SS-GIM patients, the average time per patient was 49.7 minutes $(n=31)$ spread over 3.46 days. The average time for surgical oncology/general surgery patients averaged 28.1 minutes ( $n=29$ patients) over 6.56 days. When the difference in PTPP is combined with LOS, replacing 12 - general surgery beds with SS-GIM patients, PTPP increases by $50 \%$ (lowest estimate: GIM vs. Surgery) to $90 \%$ (highest estimate: SS-GIM vs. surgical oncology/general surgery).

Conclusion: Adjusting the mix of patients on a unit significantly affects workload and justifies an increase in pharmacist full time equivalents from 1.0 to between 1.5 and 1.9 .

\section{Evaluation of Interventions to Improve Manage- ment of Behavioural and Psychological Symptoms of Dementia in a Residential Care Facility \\ Tremblay L, ${ }^{1}$ Siu J, ${ }^{1}$ De Lemos J, ${ }^{1}$ Chang J, ${ }^{1}$ Kelly J, ${ }^{2}$ Wilkins-Ho $M,{ }^{3}$ Wakefield $R^{3}$ \\ ${ }^{1}$ Lower Mainland Pharmacy Services, Vancouver, BC \\ ${ }^{2}$ Faculty of Pharmaceutical Sciences, University of British Columbia, \\ Vancouver, $B C$ \\ ${ }^{3}$ Vancouver Coastal Health, Vancouver, BC}

Background: An estimated $80 \%$ of nursing home residents with dementia are affected by behavioural and psychological symptoms of dementia (BPSD). Behavioural measures are the first-line treatment for BPSD, with pharmacological measures only recommended if these fail. In the elderly with dementia, antipsychotics increase absolute mortality rate by $1 \%$ and are only proven to be effective for aggression, agitation and psychosis. Despite this, antipsychotic prescribing continues to increase. A practice guideline for BPSD management and panel of Quality Actions assessments were recently implemented in a Canadian health authority to improve management of BPSD.

Objectives: Our primary outcome was to determine if the proportion of residents receiving appropriate initial antipsychotic therapy increased after implementation of interventions. Our secondary outcomes were to determine if reassessment for efficacy and tapering of antipsychotics improved after implementation of interventions.

Methods: We conducted a retrospective observational study. We included residents with dementia at a residential care facility with an antipsychotic initiated during specific time periods and excluded those with an antipsychotic order of under 24 hours. By consensus, "appropriate antipsychotic initiation" was defined as low dose initiated, target symptom documented and appropriate, and behavioural measures documented before and during antipsychotic therapy.

Results: Forty-nine residents were included in total; 22 residents preintervention and 27 post-intervention. The proportion of residents receiving appropriate initial antipsychotic therapy was not significantly increased between pre- and post-intervention time periods. Lack of behavioural measures was the largest contributor for inappropriate antipsychotic initiation. There was a trend towards increased rates of reassessment for efficacy and no difference in rates of reassessment for tapering between pre- and post-intervention time periods.

Conclusions: Our study failed to show an increase in appropriateness of antipsychotic initiation between pre- and post-intervention time periods. Future directions should focus on improving implementation of behavioural measures to improve management of BPSD.

\section{Single versus Dual Antiplatelet Therapy Following Transcatheter Aortic Valve Implantation: A Systematic Review}

Turgeon $R^{1}$, Barry $A^{2}$

${ }^{1}$ Faculty of Pharmaceutical Sciences, University of British Columbia, Vancouver, $B C$

${ }^{2}$ Faculty of Pharmacy and Pharmaceutical Sciences, University of Alberta, Edmonton, $A B$

Background: Transcatheter aortic valve implantation (TAVI) is a viable alternative to surgical aortic valve replacement or medical management in individuals with calcific aortic stenosis at high-risk for surgical complications or who are not surgical candidates. Guidelines currently recommend dual antiplatelet therapy (DAPT) with acetylsalicylic acid (ASA) and clopidogrel for 1 to 6 months following TAVI primarily based on expert consensus.

Objective: To evaluate the efficacy and safety of DAPT compared to single antiplatelet therapy in patients undergoing TAVI.

Methods: CENTRAL, EMBASE, MEDLINE and unpublished sources of literature were searched from inception to July 2014. Included were randomized controlled trials (RCTs), cohort and case-control studies that compared DAPT to single antiplatelet therapy post-TAVI. Risk of bias for RCTs was assessed using the Cochrane Risk of Bias Tool. The Newcastle-Ottawa Scale was used to evaluate the quality of cohort and case-control studies. Outcomes of interest included all-cause mortality, major thrombotic events and bleeding events.

Results: Four articles met the inclusion criteria (2 RCTs and 2 cohort studies) for a total of 662 patients. Included trials compared the combi- 
nation of ASA plus clopidogrel to ASA alone. Duration of DAPT ranged from 1 to 6 months. All included studies were deemed to be at high-risk of bias and could not be meta-analyzed due to selective outcome reporting and variable follow-up. Qualitative analysis of individual studies demonstrated no statistically significant reduction in all-cause mortality with DAPT compared to single antiplatelet therapy. Furthermore, DAPT did not reduce thrombotic events and resulted in a similar or higher risk of bleeding.

Conclusions: Current published evidence, though limited by low methodological quality, suggests a lack of benefit and potential harm with DAPT compared to single antiplatelet therapy in patients post-TAVI Therefore, the routine use of DAPT in these patients should be reevaluated until more evidence is available.

\section{Evaluation of Enoxaparin Pharmacokinetics and Pharmacodynamics to Develop Dose Banding Based on Total Body Weight and Renal Function}

Feng $T^{2}$ Walker SE, ${ }^{1,2}$ Bartle B, ${ }^{1,2}$ Diamantouros $A^{1,2}$

${ }^{1}$ Department of Pharmacy, Sunnybrook Health Sciences Centre, Toronto, ON

${ }^{2}$ Leslie Dan Faculty of Pharmacy, University of Toronto, Toronto, ON

Background: Enoxaparin's clinical efficacy and safety are occasionally measured by anti-Xa levels. Pharmacokinetic parameters based on antiXa concentrations change as a function of total body weight (TBW) and renal function. Most available dose banding charts to do not appear to have rigorously considered the large body of published pharmacokinetic data.

Objectives: To create an enoxaparin dosing banding table with doses rounded to the nearest pre-filled syringe size, based on TBW and renal function using published pharmacokinetic parameters.

Methods: A MEDLINE and EMBASE search yielded 31 studies with pharmacokinetic and/or pharmacodynamic data. Weighted mean kinetic data (half-life, volume, clearance) from patients being treated for acute thromboembolic events in published randomized controlled trials was calculated. A relationship between the volume and TBW and between half-life and renal function was generated. Steady state antiXa peak concentrations (AXa-max) and area-under-the-curve (AUC) were simulated using Monte Carlo methods. Doses were selected, optimizing efficacy while minimizing bleeding, and rounding to the nearest pre-filled syringe size for 7 TBW and 4 creatinine clearance bands.

Results: A relationship for volume vs. total body weight from 5 studies determined a weighted average relationship for volume: $\mathrm{V}(\mathrm{L})=$ $0.06511 \mathrm{TBW}(\mathrm{kg})-0.63455 ; \mathrm{n}=1127$ and for half-life as a function of creatinine clearance: Half-Life $(\mathrm{hr})=-1.103 \ln (\mathrm{CrCl})+7.5339 ; \mathrm{n}=259$. Doses achieving steady state AXa-max targets of $1.0 \mathrm{IU} / \mathrm{mL}$, but not exceeding 1.8 and an AUC between 73-97IU*hr/mL were calculated and displayed in the Table.

\begin{tabular}{lrcrc} 
& \multicolumn{4}{c}{ Creatinine Clearance } \\
\cline { 2 - 5 } $\begin{array}{l}\text { Total Body } \\
\text { Weight(kg) }\end{array}$ & $\begin{array}{r}50-100 \\
\mathrm{~mL} / \mathrm{min}\end{array}$ & $\begin{array}{c}30-50 \\
\mathrm{~mL} / \mathrm{min}\end{array}$ & $\begin{array}{c}15-30 \\
\mathrm{~mL} / \mathrm{min}\end{array}$ & $\begin{array}{c}0-15 \\
\mathrm{~mL} / \mathrm{min}\end{array}$ \\
\hline$<47$ & $40 \mathrm{mg}$ BID & $30 \mathrm{mg}$ BID & $30 \mathrm{mg} \mathrm{BID}$ & $40 \mathrm{mg}$ OD \\
\hline $48-63$ & $60 \mathrm{mg}$ BID & $60 \mathrm{mg}$ BID & $40 \mathrm{mg} \mathrm{BID}$ & $40 \mathrm{mg}$ BID \\
\hline $64-78$ & $80 \mathrm{mg}$ BID & $80 \mathrm{mg}$ BID & $60 \mathrm{mg} \mathrm{BID}$ & $40 \mathrm{mg} \mathrm{BID}$ \\
\hline $79-96$ & $100 \mathrm{mg}$ BID & $80 \mathrm{mg}$ BID & $80 \mathrm{mg} \mathrm{BID}$ & $60 \mathrm{mg}$ BID \\
\hline $97-115$ & $120 \mathrm{mg}$ BID & $100 \mathrm{mg}$ BID & $100 \mathrm{mg} \mathrm{BID}$ & $80 \mathrm{mg}$ BID \\
\hline $116-140$ & $150 \mathrm{mg}$ BID & $120 \mathrm{mg}$ BID & $120 \mathrm{mg} \mathrm{BID}$ & $100 \mathrm{mg}$ BID \\
\hline
\end{tabular}

Conclusions: This dose banding chart is built from pharmacokinetic data and represents a different approach to calculate weight-based doses. These recommended doses offer greater resolution for renal function and AXa-max concentrations of $1.0 \mathrm{IU} / \mathrm{mL}$ but limit large $\mathrm{AUC}$ and $\mathrm{AXa}-\mathrm{max}$ values.

\section{Adherence to Clinical Practice Guidelines for Antimicrobial Prophylaxis in Surgery

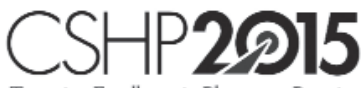 \\ Targeting Excellence in Pharmacy Practice}

Somers E, ${ }^{1}$ MacLaggan $T,{ }^{1}$ Glennie $H,{ }^{2}$ Salmon ${ }^{2}$

${ }^{1}$ Horizon Health Network, Moncton, NB

${ }^{2}$ Horizon Health Network, Saint John, NB

Background: Adherence to clinical practice guidelines for antimicrobial prophylaxis in surgery has been reported to be suboptimal in many facilities.

Objectives: The primary objective of this study was to identify the proportion of surgical patients who received appropriate perioperative antimicrobial prophylaxis within 4 hospitals.

Methods: A retrospective chart review of all patients admitted to the included hospitals for class I or II surgeries, who were discharged between September 15 and September 21, 2013, inclusive was completed. Definitions of appropriate use, choice, dose, timing, intraoperative dosing, and duration of prophylactic antimicrobial were developed from current clinical practice guidelines. Completely appropriate antimicrobial prophylaxis was defined as adherence to all 5 definitions listed above (use, choice, dose, timing, intraoperative dosing, and duration). Descriptive statistics were used to analyze data.

Results: A total of 253 patients were included in the analysis. The 5 most common surgical sites (and proportion of total surgeries) were orthopedic (36.8\%), intra-abdominal (15.9\%), gynecologic $(9.5 \%)$, urologic $(7.5 \%)$, and cardiac (7.5\%). The proportion of all surgical patients who received completely appropriate antimicrobial therapy was $40.7 \%$. The proportion of all surgical patients who received correct use, choice, dose, timing, intraoperative dosing, and duration of prophylactic antimicrobial was $90.3 \%, 88.6 \%, 62.3 \%, 91.1 \%, 84.6 \%, 83.9 \%$ respectively. Adherence to guidelines for dosing and duration of prophylactic antimicrobial were shown to be lowest. Inappropriate post-operative duration was most common in urologic surgery with $58.9 \%$ of urologic surgery patients receiving postoperative antimicrobials for greater than 24 hours. The cause of all (100\%) inappropriate dosing was under-dosing.

Conclusion: Adherence to guidelines for antimicrobial prophylaxis in surgery can be improved within the included hospitals. This study identifies antimicrobial dosing for all surgeries and post-operative antimicrobial duration in urologic surgery as potential targets for antimicrobial stewardship intervention.

\section{Follow-up Point Prevalence Survey of Antimicrobial Use in the Cardiac and Paediatric Critical Care Unit}

De Castro C, Pong S, Blinova E, Boodhan S, Richardson S, Clarke M, Zhao XY, Timberlake K, Lau E, Bitnun A, Cox P, Schwartz S, Seto W The Hospital for Sick Children, Toronto, ON

Background: A 2008 point prevalence survey in the critical care unit (CCU) of our paediatric hospital found a high rate of inappropriate antimicrobial use. Several initiatives including the Antimicrobial Stewardship Program were recently implemented. Current literature supports ongoing surveillance to evaluate the impact of such initiatives and to monitor trends over time.

Objectives: To determine the prevalence of infections and antimicrobial use in the $\mathrm{CCU}$, to assess the appropriateness of antimicrobial prescribing, and to compare results with the previous 2008 study.

Methods: In this cross-sectional study, all CCU patients receiving systemic antimicrobials during one week in October 2013 (Period A) and February 2014 (Period B) were followed until completion of antimicrobial therapy 
or discharge. Four blinded clinician assessors rated appropriateness of antimicrobials prescribed according to 9 pre-defined criteria. Disagreements on overall appropriateness were resolved during a consensus meeting. Descriptive and comparative analyses were performed by a biostatistician.

Results: Of 139 patients in CCU during both periods, 111 (80\%) received antimicrobials. A diagnosis of infection was definite in $29 \%$ and presumed in $20 \%$ of patients. Sepsis, bloodstream infections and pneumonia were the most prevalent infections. The most frequently prescribed antimicrobials were cefazolin, vancomycin, ceftriaxone, piperacillin-tazobactam, and gentamicin. Empiric therapy was the most common indication. Inappropriateness ratings ranged from 15.4 to $52.5 \%$. Post consensus meeting, 43 (39\%) patients were rated as having overall inappropriate antimicrobial use by at least 3 of 4 assessors. The most common reasons for inappropriate use were inappropriate duration, unnecessary use, and overly broad spectrum. Compared to the previous study, the prevalence of infections, antimicrobial use, and inappropriate antimicrobial prescribing were generally similar.

Conclusion: Prevalence of antimicrobial use in CCU patients remains high with a significant proportion still considered inappropriate. Further research to evaluate and resolve factors associated with inappropriate antimicrobial use in critically ill children is needed.

\section{Telepharmacy Support of an Antimicrobial Stewardship Program in a Small Rural Acute Care Hospital}

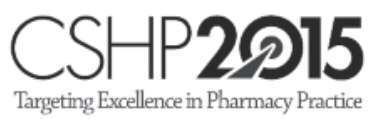

Dhaliwall S, ${ }^{2}$ Coulas $S,{ }^{1}$ Kuiack J, ${ }^{1}$ Malinowski J, ${ }^{1}$ McDonald $K^{2}$

${ }^{1}$ St. Francis Memorial Hospital, Barry's Bay, ON

${ }^{2}$ North West Telepharmacy Solutions, Brampton and Deep River, ON

Background: Accreditation Canada identified an Antimicrobial Stewardship Program (ASP) as a Required Organizational Practice in all acute care hospitals. Clinical pharmacists have been identified as a key member of a successful ASP. This small rural acute care hospital utilizes a telepharmacy model of care with a remote clinical pharmacist.

Description: The hospital is a 20- bed acute care hospital with no on-site clinical pharmacist and requested the remote clinical pharmacist to help lead the ASP to prepare for Accreditation in December 2013.

Action: The remote clinical pharmacist performed a gap analysis to identify areas requiring improvement for a successful ASP which included the need for an Antimicrobial Stewardship committee, an IV to PO conversion program for antibiotics, development of guidelines and clinical pathways for common infections, hospital specific antibiogram, and prospective audit with intervention and feedback. The remote clinical pharmacist participated in meetings with nurses, physicians and other key stakeholders using OTN videoconference technology to develop a plan for the ASP which was approved by the Medical Advisory Committee. The remote clinical pharmacist started prospective data collection in September 2013.

Evaluation: The implemented and innovative ASP was accepted by Accreditation Canada in December 2013.

Implication: Small rural and remote acute care hospitals without access to an on-site clinical pharmacist can successfully implement and maintain an ASP by seeking support from experienced remote clinical pharmacists.

\section{Evaluation of Inhaled Corticosteroid Prescribing for Chronic Obstructive Pulmonary Disease in Family Medicine Teaching Units}

\section{Falk J, Sandhu J \\ University of Manitoba, Winnipeg, $M B$}

Background: Inhaled corticosteroids (ICS) provide modest benefits and concerning harms in clinical trials of chronic obstructive pulmonary disease (COPD) patients. Their use in this population continues to be promoted, but prescribing patterns have not been well studied.

Objective: To study the utilization and prescribing patterns of ICS in COPD management in a family medicine setting.

Methods: A retrospective electronic medical record review at two family medicine teaching clinics was performed. Included were patients 35 years of age or older who either had an ICD-9 COPD diagnosis or billing code or who were using tiotropium. Patients with asthma were excluded. Patient characteristics were collected for the COPD population with specific analysis performed on patients recently started on ICS within the last year, including the number of patients who met current guideline criteria for ICS initiation, reasons for not meeting criteria, and occurrence of benefit/harm discussions prior to initiation.

Results: Of the 137 patients analyzed, 41 (30\%) were currently using ICS. Of these, $35 \%, 43 \%$, and $22 \%$ were on high, moderate, and low dose ICS, respectively. Seven patients were recently started on ICS. Of these, 5 met 2007 Canadian guideline criteria for ICS initiation based on having one $(n=4)$ or more $(n=1)$ exacerbations/year, but only 1 had undergone appropriate trials of other therapies prior to ICS initiation. Five patients were initiated on a fluticasone/salmeterol combination inhaler after inadequate response to only salbutamol and ipratropium. Only two patients met the 2011 American/European guideline criteria, and 1 patient met the 2013 international GOLD criteria. No documentation existed regarding discussions of potential benefits, harms or costs of ICS prior to these initiations.

Conclusion: Although ICS were generally initiated in patients meeting Canadian COPD exacerbation criteria, most had not previously undergone adequate trials of other COPD inhalers and most did not meet the newer international criteria.

\section{Stability of an Epidural Analgesic Admixture Containing Ropivacaine and Epinephrine in Cassette Reservoirs}

Perks $B,{ }^{1}$ Law $S,{ }^{1}$ Iazzetta J, ${ }^{1,2}$ Walker SE ${ }^{1,2}$

${ }^{1}$ Department of Pharmacy, Sunnybrook Health Sciences Centre, Toronto, ON

${ }^{2}$ Leslie Dan Faculty of Pharmacy, University of Toronto, Toronto, ON

Background: Admixtures containing local anesthetics and epinephrine are increasingly used in epidural pain management. Published reports on the stability of ropivacaine-epinephrine containing admixtures (with or without opioids) are lacking.

Objective: The objective of this study was to evaluate the stability of epinephrine $0.005 \mathrm{mg} / \mathrm{mL}$ in combination with ropivacaine $0.125 \%$, $0.3 \%$ or $0.5 \%$ in cassette reservoirs at $23 \mathrm{C}$ or $4 \mathrm{C}$, with or without protection from light.

Methods: On study-day zero, 32 solutions of epinephrine and ropivacaine were prepared in reservoir cassettes (CADDC) and stored at $4 \mathrm{C}$ and $23 \mathrm{C}$ protected from fluorescent room light. An additional solution of $0.005 \mathrm{mg} / \mathrm{mL}$ epinephrine with $0.3 \%$ ropivacaine, also prepared in reservoir cassettes (CADDC), was exposed to normal fluorescent light. Samples were assayed on 15 study days over a 66-day period using a 
validated, stability-indicating, liquid chromatographic method with ultraviolet detection. Stability was defined as the time taken for the concentration to decline to $90 \%$ of the initial concentration, based on the fastest degradation rate determined from the $95 \%$ confidence interval.

Results: The analytical method was accurate $(<2.0 \%$ deviation $)$ and reproducible (average CV\% <2\%). Epinephrine and ropivacaine solutions retained more than $95 \%$ of their initial concentration for 31 days and more than $90 \%$ of the concentration for 66 days regardless of temperature, concentration or light protection. The time to achieve $90 \%$ of the initial concentration, based on the $95 \%$ confidence interval, exceeded the study duration of 66 days.

Conclusions: Epinephrine and ropivacaine solutions stored in cassette reservoirs retained more than $90 \%$ of the initial concentration over a period of 66 days when stored at $4 \mathrm{C}$ or $23 \mathrm{C}$. Exposure of the solutions to normal fluorescent light did not affect stability. When assigning a beyond use date (BUD), USP 797 recommendations should be followed.

\section{Extended Stability of Sodium Phosphate Solutions in Polyvinylchloride Bags}

Perks $B,{ }^{1}$ Iazzetta J, ${ }^{1,2}$ Chan PC, ${ }^{3,4}$ Law $S,{ }^{1}$ Brouzas $A,{ }^{3}$ Walker $S E^{1,2}$ ${ }^{1}$ Department of Pharmacy, Sunnybrook Health Sciences Centre,

Toronto, ON

${ }^{2}$ Leslie Dan Faculty of Pharmacy, University of Toronto, Toronto, ON

${ }^{3}$ Department of Biochemistry, Sunnybrook Health Sciences Centre,

Toronto, $O N$

${ }^{4}$ Faculty of Medicine, University of Toronto, Toronto, $\mathrm{ON}$

Background: ISMP has suggested and Accreditation Canada has mandated the elimination of concentrated electrolytes from patient care areas. Sodium phosphate injection is one such concentrated electrolyte. Providing sodium phosphate as a dilute solution prepared by pharmacy would comply with the required organization practice. However, to our knowledge, there have been no published reports documenting the extended stability of sodium phosphate injection in iv solutions.

Objective: The objective of this study was to evaluate the stability of 30 and $150 \mathrm{mmol} / \mathrm{L}$ of sodium and phosphate in $5 \%$ dextrose in water (D5W) or $0.9 \%$ sodium chloride (NS) solutions stored in PVC bags at 23C or 4C over 63 days.

Methods: On study-day zero, 30 and $150 \mathrm{mmol} / \mathrm{L}$ solutions of sodium phosphate in D5W or NS were prepared in PVC bags and stored at 4C and 23C. During the 63-day study period the concentration of sodium and phosphate was determined on 12 study days. A beyond-use date was determined as the time taken for the concentration to decline to $90 \%$ of the initial concentration, based on fastest degradation rate determined from the $95 \%$ confidence interval (CI) for both sodium and phosphate.

Results: The analytical method was accurate (2.06\% deviation) and reproducible (CV\%), averaging $1.32 \%$ for standards and Quality Control samples. Sodium and phosphate retained more than $94 \%$ of the initial concentration over the 63 study period. The time to achieve $90 \%$ of the initial concentration, based on the $95 \%$ confidence interval, exceeded the 63 day study period, regardless of temperature, concentration or solution.

Conclusions: We conclude that sodium phosphate solutions at concentrations of 30 or $150 \mathrm{mmol} / \mathrm{L}$ diluted in either $\mathrm{NS}$ or $\mathrm{D} 5 \mathrm{~W}$ retain more than $94 \%$ of the initial concentration over a period of 63 days when stored at $4 \mathrm{C}$ or $23 \mathrm{C}$. When assigning a beyond use date (BUD), USP 797 recommendations should be followed.

\section{Stability of $100 \mathrm{mg} / \mathrm{mL}$ Ertapenem in Syringes and the Manufacturer's Glass Vial at $4 \mathrm{C}$ and 23C}

Law $S,{ }^{1}$ Iazzetta J, ${ }^{1,2}$ Perks $B,{ }^{1}$ Walker $S E^{1,2}$

${ }^{1}$ Department of Pharmacy, Sunnybrook Health Sciences Centre, Toronto, ON

${ }^{2}$ Leslie Dan Faculty of Pharmacy, University of Toronto, Toronto, ON

Background: Prophylactic administration of ertapenem as a single $1 \mathrm{~g}$ IV dose has been shown to reduce sepsis after prostate biopsy. Previous ertapenem stability studies have not evaluated concentrations of $100 \mathrm{mg} / \mathrm{mL}$.

Objective: The objective of this study was to evaluate the stability of ertapenem, reconstituted with $0.9 \%$ sodium chloride to achieve a final concentration of $100 \mathrm{mg} / \mathrm{mL}$, and stored in polypropylene syringes or the manufacturer's original glass vial.

Methods: On study-day zero, $100 \mathrm{mg} / \mathrm{mL}$ solutions of ertapenem were packaged in polypropylene syringes or the manufacturer's glass vials and stored at 4C and 23C unprotected from fluorescent room light. Samples were assayed using a validated, stability-indicating liquid chromatographic method with ultraviolet detection. A beyond-use date was determined as the time taken for the concentration to decline to $90 \%$ of the initial (day 0 ) concentration, based on fastest degradation rate determined from the 95\% confidence interval (CI).

Results: Reconstituted solutions stored in polypropylene syringes exhibited a degradation rate of approximately $2.99 \%$ per day at $4 \mathrm{C}$ and $19.0 \%$ per day stored at $23 \mathrm{C}$. When stored in the manufacturer's glass vial, the degradation rate was similar, approximately $2.95 \%$ per day at $4 \mathrm{C}$ and $19.1 \%$ per day during storage at $23 \mathrm{C}$. Analysis of variance detected differences in percent remaining due to temperature $(\mathrm{p}<0.0015)$, study day $(p=0.0052)$ but not container $(p=0.9790)$. When a $95 \%$ confidence interval for the degradation rate was determined, solutions retained at least $90 \%$ of the initial concentration after storage at 2.9 days at $4 \mathrm{C}$ or approximately 0.44 days ( $~ 10$ hours and 40 minutes) at room temperature.

Conclusion: A $100 \mathrm{mg} / \mathrm{mL}$ ertapenem solution stored in a polypropylene syringe or manufacturer's vial, will retain more than $91.5 \%$ of the initial concentration when stored for 48 hours at $4 \mathrm{C}$ and an additional 2 hours at $23 \mathrm{C}$.

\section{Utilization of Dexmedetomidine in Patients Admitted to a Tertiary Care Medical Surgical Intensive Care Unit}

Lovering $S,{ }^{1}$ Singh $J,{ }^{2}$ Carter $A^{2,3}$

${ }^{1}$ Leslie Dan Faculty of Pharmacy, University of Toronto, Toronto, ON

${ }^{2}$ Toronto Western Hospital, University Health Network, Toronto, ON

${ }^{3}$ Department of Pharmacy Services, University Health Network,

Toronto, ON

Background: Patients on mechanical ventilation may require sedation to improve comfort and ventilator synchrony, but traditional sedatives can increase the risk of ICU delirium. The alpha-2 adrenergic agonist dexmedetomidine may be associated with less delirium, however it is considerably more expensive. It was added to our tertiary care hospital formulary in September 2011 for use in delirious patients who are anticipated to be ready for extubation within 48 hours.

Objective: To examine the use of dexmedetomidine and adherence to prescribing restrictions among patients admitted to our tertiary care medical surgical intensive care unit.

Methods: A retrospective chart review of patients prescribed dexmedetomidine from September 1, 2013 to November 30, 2013. Adherence to restricted use criteria was ascertained using the following three criteria: (1) readiness to wean, as per fixed respiratory parameters, (2) presence of delirium, as defined by the Confusion Assessment Method for the Intensive Care Unit (CAM-ICU), (3) duration of use less than 48 hours. Descriptive statistics were used for all outcomes assessed. 
Results: Six patients were identified for inclusion. Adherence to all three prescribing restrictions was $17 \%(n=1)$. Eighty-three percent $(n=5)$ met the criteria for readiness to wean towards extubation and $33 \%(n=2)$ had a positive CAM-ICU assessment. CAM-ICU ratings were not documented or could not be assessed for $67 \%(n=4)$ despite $50 \%(n=2)$ of these patients actively receiving delirium treatment. Eighty-three percent $(n=5)$ were administered dexmedetomidine for less than 48 hours. Fifty percent $(n=3)$ were extubated during dexmedetomidine administration.

Conclusion: Dexmedetomidine was not used in strict accordance to restriction criteria in the majority of patients. The greatest area for improvement in meeting restriction criteria was for CAM-ICU assessments. Research examining the barriers to CAM-ICU screening and documentation is warranted.

\section{Review of the Safety of Disease-Modifying Anti-rheumatic Drug Therapy in Patients with Chronic Kidney Disease}

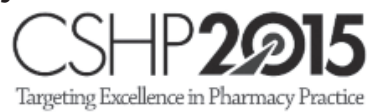

Carpenter $T,{ }^{1}$ Hall J, ${ }^{2}$ Katz $S^{1}$

${ }^{I}$ Division of Rheumatology, University of Alberta, Edmonton, $A B$

${ }^{2}$ Faculty of Pharmacy and Pharmaceutical Sciences, University of

Alberta, Edmonton, $A B$

Background: Recommendations regarding the use of disease modifying anti-rheumatic drugs (DMARDs) in both chronic kidney disease and renal replacement therapy are limited in guiding clinicians in the choice of therapy.

Objective: We aimed to review the available evidence for disease modifying agents for patients with inflammatory arthritis and co-existing chronic kidney disease in order to assist clinicians in prescribing safe and effective therapy.

Methods: Medline (Ovid, 1946-July 28, 2014) and EMBASE (Ovid, 1974-July 28, 2014) database searches were conducted to identify literature related to the use of DMARDs in patients with reduced renal function. Case reports or series, cohort studies, pharmacokinetic studies, and randomized controlled studies that reported efficacy or safety parameters in English were eligible for inclusion.

Results: Ninety-three studies examining DMARDs in chronic kidney disease were identified, the vast majority of which were case reports or case series. While limited, the current literature suggests that antimalarials, azathioprine and TNF $\alpha$ inhibitors can be used safely in patients with chronic kidney disease with appropriate dosing adjustments. In patients receiving renal replacement therapy, antimalarials, leflunomide, $\mathrm{TNF} \alpha$ inhibitors, and non-TNF biologics appear to be safe, but data suggest that methotrexate and gold are unsafe.

Conclusion: Many DMARDs are likely safe to use in patients with inflammatory arthritis and co-existing chronic kidney disease. However, more prospective studies are needed to support these results and to guide the creation of clinical practice guidelines for this population.

\section{Recherche en pratique pharmaceutique : des recettes et astuces en ligne}

Bérard C, ${ }^{1}$ Tanguay $C,{ }^{1}$ Bussières $J F^{1,2}$

${ }^{1}$ Département de pharmacie et Unité de recherche en pratique pharmaceutique, CHU Sainte-Justine, Montréal, QC

${ }^{2}$ Faculté de pharmacie, Université de Montréal, Montréal, QC
Contexte : Il existe relativement peu de recherche en pratique pharmaceutique. Les étudiants et pharmaciens hospitaliers impliqués dans ce domaine sont formés le plus souvent par eux-mêmes à partir d'un nombre limité d'ouvrages.

Description : Afin de soutenir la formation de ces jeunes professionnels, nous avons retenu le concept d'un « livre de recettes » sur la recherche en pratique pharmaceutique issu de notre expertise, de nos réalisations et d'une revue de la littérature. Ce livre est co-rédigé par les étudiants en formation de notre centre et les chercheurs de l'équipe. Afin d'assurer le partage des connaissances, l'outil a été mis en ligne et prend la forme d'articles structurés. Les articles comportent une mise en contexte, des connaissances théoriques et pratiques ainsi que des astuces de notre équipe de recherche, basées sur des exemples concrets de projets de recherche en pratique pharmaceutique réalisés par notre équipe.

Action : À partir de l'idée originale, nous avons identifié 13 thèmes (par exemple mise en place, revue de la littérature, statistiques, écriture, valorisation, suivi) et 29 articles (par exemple identifier un problème, commencer un projet, choisir un devis, faire une revue de la littérature reproductible, analyser les données, créer une affiche). Six articles ont été finalisés à ce jour.

Évaluation : Ces articles sont utilisés dans la formation des nouveaux étudiants, qui sont également invités à commenter leur contenu. Un suivi de la consultation de ces articles en ligne est effectué.

Répercussions : À notre connaissance, il s'agit de la première initiative visant à rédiger un ouvrage en ligne soutenant la recherche en pratique pharmaceutique et se basant sur des exemples concrets de projets de recherche. Le partage de cet outil en ligne à la communauté pharmaceutique est susceptible de contribuer au développement de cette recherche nécessaire aux décideurs et cliniciens du réseau de la santé.

\section{Publications comportant des retombées négatives de l'activité pharmaceutique}

Guérin $A^{1}$, Leroux $A^{1}$, Lebel $D,{ }^{1}$ Bussières $J F^{1,2}$

${ }^{1}$ Département de pharmacie et Unité de recherche en pratique pharmaceutique, Centre hospitalier universitaire Sainte-Justine, Montréal, QC ${ }^{2}$ Faculté de pharmacie, Université de Montréal, Montréal, QC

Justification : Il existe une tendance à davantage publier des résultats ayant obtenu un résultat positif que des résultats négatifs. Ce biais de publication est un frein à l'avancement des connaissances.

Objectifs : L'objectif était d'évaluer le taux de publications incluant au moins un indicateur de retombées négatif de l'activité pharmaceutique au sein de la littérature et de présenter un portrait de ces articles.

Méthodologie et démarche de l'étude : Une recherche bibliographique a été réalisée sur PubMed de 2008 à 2014. Les articles présentant le rôle, les interventions et les retombées des pharmaciens ont été sélectionnés et analysés par deux assistantes de recherche. Le taux de publication comportant au moins un indicateur de retombées négatif a été calculé. La profession des auteurs a été collectée. Les indicateurs de retombées négatifs de l'activité pharmaceutiques ont été comptabilisés.

Résultats : Un total de 203 articles ont été inclus. Le taux de publication comportant au moins un indicateur de retombées négatifs était de 5,4\% $(11 / 203)$. Les premiers auteurs de chaque article étaient tous pharmaciens. Dix indicateurs de retombées négatives de l'activité pharmaceutiques ont été comptabilisés, à savoir les coûts de médicaments, les coûts totaux, le nombre de divergences de prescription, le nombre d'interactions médicamenteuses, le nombre de complications d'hyperglycémie, la durée de séjour, le taux de réadmission aux urgences, l'observance aux corticostéroïdes inhalés et la durée appropriée de traitement. 
Conclusion : Cette revue documentaire met en évidence le fait qu'il existe peu de données sur les retombées négatives de l'activité pharmaceutique. Ceci n'est pas étonnant compte tenu de l'émergence de la recherche évaluative en pharmacie et du biais de publication commun à toutes les professions.

\section{Comparaison du niveau d'accord à des énoncés sur l'éthique pharmaceutique entre étudiants en pharmacie et pharmaciens hospitaliers canadiens}

Guérin $A^{l}$, Lebel $D^{l}$, Bussières $J F^{1,2}$

${ }^{1}$ Département de pharmacie et Unité de recherche en pratique

pharmaceutique, CHU Sainte-Justine, Montréal, QC

${ }^{2}$ Faculté de pharmacie, Université de Montréal, Montréal, QC

Justification : L'éthique fait partie intégrante de la pratique pharmaceutique.

Objectifs : Comparer le niveau d'accord d'étudiants en pharmacie et de pharmaciens hospitaliers sur des énoncés portant sur l'éthique pharmaceutique.

Méthodologie et démarche de l'étude : Enquête effectuée du $1^{\mathrm{er}}$ octobre 2012 au 2 décembre 2013 pour les étudiants et du 29 août 2014 au 2 septembre 2014 pour les pharmaciens. Un questionnaire de huit sections et 43 énoncés a été développé portant sur les sujets suivants : formation et études (5 questions), recherche clinique (7), mise sur le marché et publicité (5), évaluation et données probantes (5), dispensation de médicaments (4), soins pharmaceutiques (9), aspects économiques (6) et déontologie (2). Une échelle de Likert à quatre choix a été utilisée afin de mesurer le niveau d'accord. L'issue principale était la différence entre le niveau d'accord des étudiants en pharmacie et des pharmaciens hospitaliers. Le test du chi-carré a été utilisé. Une valeur de p inférieur à 0,05 est considérée significative.

Résultats : Un total de 347 étudiants et de 398 pharmaciens ont répondu à l'enquête. Il y avait une différence statistiquement significative en ce qui concerne le niveau d'accord pour 29 énoncés sur les 43. Les différences portaient sur les huit sections du questionnaire, soit formation et études (3/5 questions significativement différentes), recherche clinique (2/7), mise sur le marché et publicité (2/5), évaluation et données probantes (4/5), dispensation de médicaments (4/4), soins pharmaceutiques (5/9), aspects économiques (6/6) et déontologie (2/2). Les résultats confirment une grande sensibilité éthique des étudiants en pharmacie et pharmaciens hospitaliers vis-à-vis de la plupart de ces énoncés.

Conclusion : Cette étude montre qu'il existe une différence entre pharmaciens et étudiants en pharmacie sur des énoncés portant sur l'éthique pharmaceutique.

\section{Littérature sur le rôle et les retombées du pharmacien : perceptions d'étudiants canadiens}

Guérin $A,{ }^{1}$ Lebel D, ${ }^{1}$ Bussières JF $F^{1,2}$

${ }^{1}$ Département de pharmacie et Unité de recherche en pratique pharmaceutique, Centre Hospitalier Universitaire Sainte-Justine, Montréal, QC

${ }^{2}$ Faculté de pharmacie, Université de Montréal, Montréal, QC

Justification : Les facultés de pharmacie canadiennes travaillent sur la transformation des programmes de baccalauréat. Alors que les étudiants sont exposés au cours de leur cursus aux preuves sur la pharmacothérapie, l'exposition aux preuves sur le rôle et retombées du pharmacien est limitée.
Objectifs : Lobjectif principal était d'évaluer la perception d'étudiants canadiens vis-à-vis de la littérature sur le rôle et retombées du pharmacien. Lobjectif secondaire était d'évaluer leur perception vis-à-vis du site Internet Impact Pharmacie recensant les preuves sur le rôle et retombées du pharmacien.

Méthodologie : Nous avons développé et pré-testé sur des étudiants en pharmacie un questionnaire de 19 questions visant à explorer la perception des étudiants vis-à-vis de la littérature sur le rôle et les retombées du pharmacien et leurs premières impressions sur le site Impact Pharmacie. Nous avons exposé une cohorte de $3^{\text {ème }}$ année à la littérature sur le rôle et les retombées du pharmacien. Le site Impact Pharmacie servait de support à la présentation. Nous avons administré le questionnaire et des statistiques descriptives ont été réalisées.

Résultats : Un total de 121 étudiants a participé au sondage (93\% des étudiants). Quatre-vingt-neuf pourcent (108/121) des étudiants étaient d'accord pour dire que l'exposition d'un pharmacien à des preuves sur le rôle et les retombées du pharmacien amène des changements de pratique. Quatre-vingt-neuf pourcent (105/118) étaient d'accord pour dire que ces preuves sont utiles pour la décision de gestionnaires. Par ailleurs, 37\% (44/120) des étudiants ont déclaré que les enseignements relatifs à l'évaluation des pratiques professionnelles n'incluent pas systématiquement des preuves. Les étudiants considéraient le site Impact Pharmacie pertinent et utile pour la formation des pharmaciens.

Conclusion : Les étudiants canadiens perçoivent la littérature sur leurs rôles et retombées comme utile à leur formation. L'intégration de cette littérature peut être faite à l'aide du site Impact Pharmacie.

\section{Démarche pour la mise à niveau de soins pharmaceutiques : l'exemple de l'immunisation}

Guérin $A^{1}$, Bédard $P^{1}$ Lebel $D,{ }^{1}$ Bussières $J F^{1,2}$

${ }^{1}$ Département de pharmacie et Unité de recherche en pratique pharmaceutique, Centre Hospitalier Universitaire Sainte-Justine, Montréal, QC

${ }^{2}$ Faculté de pharmacie, Université de Montréal, Montréal, QC

Justification : L'administration d'un médicament par injection (p.ex. la vaccination) est permise aux pharmaciens dans au moins six provinces canadiennes. En outre, le Protocole d'immunisation du Québec ne précise actuellement pas de rôle spécifique pour le pharmacien.

Objectifs : Mettre à jour le niveau de pratique utilisé en soins pharmaceutiques en immunisation.

Méthodologie et démarche de l'étude : Il s'agit d'une étude descriptive avec revue documentaire menée dans un centre hospitalier universitaire mère-enfant canadien. La démarche de mise à niveau proposée comporte trois étapes soit une revue de la documentation, une description du profil du secteur et une description de la mise à jour du niveau de pratique.

Résultats : La revue de la documentation a permis de recenser 19 articles sur le rôle du pharmacien en immunisation. Nous n’avons recensé aucune activité pharmaceutique spécifique reposant sur des données de très bonne qualité. En 2013-2014, il y avait une dépense annuelle en vaccins de 4227 dollars, une dépense annuelle en médicaments de 27633944 dollars, et un total de 9254 doses de produits immunisants prescrits chez 3544 patients. Selon la revue de la littérature, la mise à jour envisagée de l'activité d'immunisation inclut notamment un bilan comparatif ciblant les besoins en immunisation, la consultation systématique des dossiers pharmacologiques des patients hospitalisés depuis plus d'un mois afin de s'assurer l'adhésion au Protocole d'immunisation du Québec, la déclaration systématique des effets indésirables vaccinaux et l'implantation de capsules d'informations sur les nouveautés vaccinales. 
Conclusion : Cette étude descriptive met en évidence le rôle du pharmacien en immunisation dans un centre hospitalier de soins universitaire. Il existe peu de données sur le rôle du pharmacien pour cette activité; notre revue documentaire a toutefois permis d'identifier une quinzaine de changements et d'améliorations à nos pratiques actuelles.

\section{The Evaluation of Paclitaxel Hypersensitivity Reactions Following the Discontinuation of Prophylactic Pre-medications}

\author{
Meyer $C,{ }^{1}$ Raymond $C,{ }^{1}$ Lee ${ }^{2},{ }^{2}$ Amir $E,{ }^{3}$ Mackay $H,{ }^{2} \mathrm{Oza} A,{ }^{4}$ \\ Warr $D,{ }^{2} \mathrm{Ng} \mathrm{P}^{2}$ \\ ${ }^{1}$ Pharmacy, University Health Network, Toronto, ON \\ ${ }^{2}$ Medical Oncology, Princess Margret Hospital, Toronto, ON \\ ${ }^{3}$ Medical Oncology, Princess Margaret Cancer Centre, Toronto, ON \\ ${ }^{4}$ Department of Medical Oncology and Hematology, Princess Margaret \\ Cancer Centre, Toronto, ON
}

Background: Paclitaxel administration is associated with a variable rate of hypersensitivity reactions (HSRs). Such reactions are infrequent beyond the second dose. Pre-medications comprising of corticosteroids and anti-histamines are administered to reduce the risk of HSRs, but are associated with adverse effects and a longer visit time. It is unclear if pre-medications are needed beyond the second dose.

Objectives: Pre-medications were discontinued for all patients receiving paclitaxel-based regimens beyond the second dose. We sought to evaluate this practice change and hypothesize that this policy is unlikely to result in an increased rate of HSRs.

Methods: A retrospective chart review was performed over a four-month period to review the incidence of HSRs. Adult patients were included if they received paclitaxel-based chemotherapy and did not have an HSR during the first two doses. Surveys were administered to patients receiving weekly paclitaxel to evaluate patient preference. Time required to administer pre-medications was also estimated.

Results: Of 187 patients who met the inclusion criteria, 77 patients received weekly paclitaxel, seven patients received dose-dense paclitaxel every two weeks and 103 patients received paclitaxel every three weeks. Two of 111 patients receiving paclitaxel + platinum (1.80\%) and two of 76 patients receiving paclitaxel $+/$ - trastuzumab $(2.63 \%)$ had nonsevere HSRs. An average of 90 minutes of chair time per patient (per clinic visit), was saved by omitting pre-medications. Of 52 surveys, 23 (44\%) were returned and 20 patients $(86.9 \%)$ preferred treatment without pre-medications compared to their first two doses with pre-medications.

Conclusion: In patients receiving paclitaxel + platinum regimens or paclitaxel $+/$ - trastuzumab, the discontinuation of pre-medications is a safe and feasible option if a patient has not experienced a HSR during the first or second dose of paclitaxel. Omission of pre-medications has substantial time saving implications for chemotherapy chair time.

\section{Impact of Experiential Learning on the Professional and Personal Development of Undergraduate Pharmacy Students}

\section{Ho C, Morphy B, Kawano A \\ School of Pharmacy, University of Waterloo, Waterloo, ON}

Background: The School of Pharmacy at the University of Waterloo is the only undergraduate pharmacy program in Canada that includes a co-op component. Pharmacy has evolved from a dispensing-focused to a patient-oriented health care profession over the last decade. Training of new pharmacy graduates should be well-balanced in both academic and experiential settings.
Objectives: This is a qualitative study with an objective to find out how co-op experiential learning experience affects pharmacy students' professional and personal development.

Methods: Open-ended questions were used in semi-structured interviews and focus groups to allow pharmacy students, co-op employers, and faculty members to freely express their viewpoints. An inductive approach was applied when generating themes from the transcribed data collected in this study. Thematic analysis was conducted using NVivo.

Results: Main themes were identified from 19 pharmacy students' interviews, 12 co-op employers' phone interviews, and 2 faculty focus groups. Students developed confidence, identified self- and career-related discovery; they provided constructive feedback to the co-op program and shared the challenges in classroom versus real-world practice during the interviews. Co-op employers recognized students' individual growth during co-op, yet pointed out some mismatches between the curriculum and expectations in co-op during their phone interviews. Faculty members were pleased to see that students took ownership of their learning, the integration of knowledge between classroom and work placements, and students' maturity and professional growth during co-op; but were a bit concerned about the unstructured nature of co-op. Conclusion: We have made assumptions on students' professional and personal development during co-op placements. However, we attempted to use triangulation of data from co-op employers and faculty members to substantiate our findings. In future curricular development, institutions should consider a hybrid of structured and unstructured experiential education for pharmacy students to complement classroom teaching.

\section{Effectiveness of Extracurricular Journal Clubs on Pharmacy Students' Learning of Evidence-Based Medicine and Critical Appraisal}

Tsang J, Ho C, Olla W, Power M, Morphy B, Patel S, Poon C, Tong B School of Pharmacy, University of Waterloo, Waterloo, ON

Background: In hospital pharmacy practice, journal club (JC) often serves as a means of knowledge exchange among clinicians for the application of evidence to patient care.

Objective: We simulated JC in school with the objective of studying the effectiveness of voluntary student-driven JC in the learning of evidence-based medicine (EBM) and critical appraisal (CA) in undergraduate pharmacy students.

Methods: Eight one-hour JC sessions were organized by students in two consecutive academic terms as extracurricular activities. Attendance and presentations by students were voluntary. Students who attended JC were asked to complete an online questionnaire to self-report their learning and understanding of EBM and CA concepts. JC presenters were invited to focus groups to share their feedback and learning on EBM and CA skills.

Results: Attendance of each JC ranged from 25 to 50 students. 28 students completed the online questionnaire. After attending JC, 57\% students agreed or strongly agreed that they were able to critically appraise primary literature in a timely fashion; $68 \%$ believed that they were able to formulate clinically-relevant conclusions from research studies; and 57\% were confident in presenting clinical decisions based on assessment of a research study. We conducted three focus groups with 22 student presenters and a thematic analysis was performed on the transcribed data. Student presenters found themselves more proactive in seeking evidence-based clinical decisions. They strived for continuous development of their CA skills and recognized the importance of critically analyzing methods and results presented in clinical trials. 
Conclusion: Traditional didactic teaching/learning in classroom serves as an introduction to EBM and CA. JC offered pharmacy students a platform to further practice and apply their knowledge on EBM and CA skills. Students need to continuously practice these skills in order to be prepared as a medication therapy expert capable of evaluating and applying EBM in practice.

\section{An Environmental Scan of Transition Courses for Pharmacy Students Prior to Advanced Pharmacy Practice Experience Rotations}

Paw Cho Sing E, Ho C, Lee A

Leslie Dan Faculty of Pharmacy, University of Toronto, Toronto, ON

Background: During the final year of their program, pharmacy students have the opportunity to consolidate their theoretical knowledge and skills through experiential learning in the form of Advanced Pharmacy Practice Experience (APPE) rotations. However, the transition from structured learning processes in the classroom to clinical practice often poses a formidable challenge for learners. Hence, an effective transition course is needed to bridge didactic and practical education.

Description: This study aimed to scan the education literature to identify how pharmacy programs in North America have designed their transition courses to optimize student preparedness and confidence prior to clinical rotations.

Action: A comprehensive literature review was conducted on six databases (IPA, Scopus, Embase, Medline, CINAHL, and ERIC). Articles were selected for review based on relevance and with a focus on course content, structure, and impact on measurable outcomes. Refining search terms, conducting ancestry searches, and scoping the curricula of other pharmacy schools through their university-affiliated websites were completed to saturate findings.

Evaluation: Appraisal of the compiled literature involved an evaluation of the target population, setting, study design, and the statistical strength of the evidence. Commonly identified instructional approaches included assessments of learning needs, supplementary reviews of therapeutic topics, peer and near-peer teaching models, hands-on activities, and online modules. Only two studies in the pharmacy literature quantified the impact of a transition course on students' preparedness to clinical rotations.

Implications: From the sheer diversity of findings, it is clear that a proposed model for guiding the development of a transition course is needed. The rationale behind the various instructional approaches used in existing transition courses have predominantly been extrapolated from education research in other health disciplines. With the expanding landscape of contemporary pharmacy practice, it is essential for curriculum development and current pharmacists to understand how to best prepare students for their profession.

\section{Adherence to Abiraterone among the First Eighty-Six Recipients Following Its Release in Saskatchewan, Canada \\ Smith AD, ${ }^{1}$ Olson $C,{ }^{2}$ Lyons $B,{ }^{2}$ Tran $D,{ }^{3}$ Blackburn DF \\ ${ }^{1}$ Leslie Dan Faculty of Pharmacy, University of Toronto, Toronto, ON \\ ${ }^{2}$ Saskatoon Cancer Centre, Saskatoon, SK \\ ${ }^{3}$ College of Pharmacy and Nutrition, University of Saskatchewan, \\ Saskatoon, SK}

Background: Prostate cancer is the most common cause of cancer among Canadian males. In the province of Saskatchewan, patients with metastatic castration-recurrent prostate cancer (mCRPC) who have failed androgen deprivation therapy are commonly treated with docetaxel-based therapy. However, docetaxel is associated with toxic side effects and requires intravenous administration. Recent advancements in prostate cancer treatments have produced abiraterone, a chronic, orally administered, Cytochrome P 17 inhibitor. Although abiraterone offers certain advantages, its oral administration places the responsibility for optimal adherence on the patients. To our knowledge, adherence to abiraterone in a real-world setting has never been described.

Objective: The objective of this study was to measure adherence to abiraterone among the first patients to receive it in Saskatchewan, Canada.

Methods: De-identified electronic pharmacy claims were obtained from the Saskatchewan Cancer Agency. All patients with at least one dispensation for abiraterone between August 2011 and October 2013 were eligible. The primary endpoint was the percentage of patients achieving optimal adherence at six months defined as a medication possession ratio (i.e., MPR) $\geq 80 \%$.

Results: One hundred forty-one patients received abiraterone during the study period. Of these, 86 could be followed for at least six months. Optimal adherence was achieved in $82.6 \%(71 / 86)$ patients at six months with $79.1 \%$ achieving an MPR of at least $90 \%$. Of those with available follow-up to one year, $81.6 \%(31 / 38)$ maintained optimal adherence during the entire period.

Conclusions: Among the first Saskatchewan patients who have received abiraterone, medication non-adherence does not appear to present a threat to the successful treatment of patients with mCRPC. As more cancer therapies are being delivered by chronic, oral medications, non-adherence should become an important quality indicator.

\section{Development and Implementation of a Peer- Assisted Learning Model to Teach Pharmacy Students in a Clinical Trials Rotation}

\section{De Buono K, Leung B, DeLuca S}

Princess Margaret Cancer Centre, Toronto, $O N$

Background: With increased experiential education requirements for pharmacy students and limited preceptors, there is a high demand for hospital-site rotations. Peer-assisted learning (PAL) and near-peer teaching (NPT) are two methodologies that may help address this demand.

Description: During a clinical trials rotation with two pharmacists, one doctor of pharmacy student and one fourth-year student, student activities were reviewed and characterized as PAL, NPT or individual. The rotation was used as a trial to identify if PAL and/or NPT are suitable learning strategies with the intended goal of having one preceptor taking multiple students.

Action: The doctor of pharmacy student had a 5-week rotation and started one week earlier than the fourth-year student who had a 4-week rotation. In addition to individual activities, students engaged in collaborative activities with peers. Numerous activities were tailored to PAL, including protocol review and weekly topic discussions (for example Research Ethics). An NPT activity that occurred was senior peer review of a junior peer's work to provide constructive feedback.

Evaluation: Participants were asked to comment on whether they thought this model was beneficial and feasible for future rotations. For assessment, a feedback form was developed using a Likert-type scale and was provided for review to pharmacists not participating in the program. PAL was the predominant strategy utilized, likely due to the specialized nature of the rotation. 
Implications: Participants described the PAL model as a constructive and feasible model for future rotations, and also more applicable than NPT in this setting. The adoption of a PAL model may facilitate preceptors taking more than one student. The feedback form may be a useful tool to evaluate the adopted model in future rotations.

\section{Opportunities to Enhance Institutional Experiential Education: Mutually Beneficial Activities Analysis}

\section{Luong W, House N, Legal M, Loewen P \\ University of British Columbia, Vancouver, BC}

Background: Our faculty conducted a province-wide stakeholder engagement study to identify strategies to better support learners and preceptors who participate in experiential placements at hospital sites. With program expansion there is an increased need for high quality experiential placements. A key priority is to increase student involvement in patient care and site activities. Enhanced student impact or value-add at the site is likely to increase the willingness of sites to host students and will enrich the student experience.

Description: Our stakeholder engagement project recommended that $30 \%$ of a student's time be spent performing mutually beneficial activities (MBAs). These activities should be practical, appropriate for the learner's skill level, occur in real-time, and be both beneficial to the learner's education and preceptor/pharmacy department.

Action: This project utilized stakeholder feedback, literature review and informal interviews with hospital pharmacy coordinators to identify a raw list of MBAs. This list was then evaluated using an electronic survey deployed to hospital pharmacists and coordinators, and recent faculty graduates. The survey employed Likert and open-field responses. The open field responses were analyzed for themes using qualitative methods.

Evaluation: There were a total of 127 respondents. Activities were assessed based on four categories: learner preparedness, preceptor comfort, benefit to student learning, and benefit to the pharmacy department. Taking the curriculum into account, these MBAs were split into three tiers: activities all students can complete, activities students can complete with additional training, and a preceptor's "wish list".

Implications: Promoting these activities as providing benefit to both the student and patient care would not only lead to reduced workload for preceptors but also augment existing institutional pharmacy services. Many of the activities identified are current targets of the national CSHP 2015 initiative to provide a higher standard of care across Canada.

\section{Doctor of Pharmacy Students Acquire Skills in Curriculum Design and Project Management through Participation in an Education Project with Coaching Support}

Jackson L, ${ }^{2}$ Makari J, ${ }^{1,2}$ Edwards ${ }^{1},{ }^{1}$ Hehar $H,{ }^{1}$ Lo J, ${ }^{1,2}$ Lui M, ${ }^{1,2}$ Gerges $S,{ }^{1}$ Amin $F^{2} Z$ hu $L,{ }^{2}$ Do $J,{ }^{2}$ Fox $A^{2}$

${ }^{1}$ Leslie Dan Faculty of Pharmacy, University of Toronto, Toronto, ON

${ }^{2}$ Sunnybrook Health Sciences Centre, Toronto, ON

Background: Project management and curriculum design concepts are not explicitly taught in the Pharmacy curriculum. Experience in these areas may serve to cultivate leadership capacity and career development. The project requirement for final year Pharmacy students during experiential training provided an opportunity to evaluate the students acquisition of skills from exposure to these concepts and the impact of coaching support.
Description: Students were introduced to the Project Management Institute's framework and a curriculum design framework. Coaching support was provided by five staff pharmacists. The project involved an education session for nurses caring for nephrology patients. The coprimary outcomes of students' perception of the impact that the project had on their acquisition of skills and the impact of coaching support were measured through use of a feedback form and a wrap-up session. Subjective evaluation tools were created based on the project management and curriculum design components. Scoring ranged from 1 (no change) to 4 (significant improvement).

Action: Students took responsibility for tasks and the timeline. Tasks included developing the needs assessment tool, drug monitoring monographs for anemia and hyperphosphatemia, a brief oral presentation, pre- and post-tests, and nursing feedback forms.

Evaluation: Overall, students rated the extent of skills acquisition as 2.75/4 and the impact of coaching as 3.4/4. Students rated 'confidence to manage a project' and the 'administrative leadership' aspect of coaching highest. Students felt that involvement in the project helped to develop leadership skills and will be helpful for their integration into teams in future.

Implications: Pharmacists often lead or participate in clinical practice initiatives that promote optimal patient care or process improvement. This activity invariably involves project work and education of stakeholders. Acquiring project management and curriculum design skills early in a pharmacist's career can be beneficial to their future success. Students placed a high value on the coaching they received.

\section{Prevalence of Co-trimoxazole Induced Hyperkalemia in Chronic and Acute Users in a Tertiary Teaching Hospital}

Jassim Z, Moustafa R, Abdel-Aziz H Hamad Medical Corporation, Doha, Qatar

Introduction: Hyperkalemia is serious condition as it can be fatal sometime. Many drugs can cause hyperkalemia as side effect like cotrimoxazole.

Objectives: Primary: evaluate the risk of hyperkalemia in patients receiving co-trimoxazole. Secondary: 1 ) detect the changes of potassium level from baseline to 7, 14, 21, and 30 days, 2) determine the association between co-trimoxazole dose and potassium level, 3) examine the relationship between renal function and hyperkalemia

Method: A retrospective observation study of all patients treated with co-trimoxazole during Jan 2012 till Jan 2013. Exclusion criteria include patients received less than 2 doses or have no lab test. Patient's medical records (both electronic and paper-based) were used to collect required data. Data analyzed using descriptive $\&$ inferential analyses.

Result: 161 patients were included in this study. Patients were taking co-trimoxazole either as once daily (47\%) or every other day $(53 \%)$. Co-trimoxazole was taken at doses: $480 \mathrm{mg}(19.1 \%), 960 \mathrm{mg}(66 \%)$, and $1920 \mathrm{mg}$ (14.9\%). Eighty-nine patients (55.3\%) were taking other concomitant medications that may also increase potassium level (i.e. ACE-I and B-blocker). Around 26\% of the patients treated with cotrimoxazole developed Hyperkalemia during the observed time ( 42 out of 161 patients). There was no significant correlation between cotrimoxazole doses and hyperkalemia $(25.9 \%$ in $480 \mathrm{mg}, 31.2 \%$ in 960 and $28.6 \%$ in $1920 \mathrm{mg} ; \mathrm{p}=0.863$ ) in each dose group, however, $82.5 \%$ of hyperkalemia cases were associated with significant increase in serum creatinine $(\mathrm{p}=0.00)$. The highest mean change of potassium level in once daily dosing was at "baseline-7 days" interval, while it was highest at 
"baseline-30 days" interval in every other day dosing. However; none of the changes from baseline to 7,14,21 and 30 days was found to be significant.

Conclusion: Although many patients taking co-trimoxazole developed Hyperkalemia, the effect of renal function and use of other concomitant medications can't be ignored.

\section{Planning and Evaluation of a Computerized \\ Prescriber Order Entry Implementation

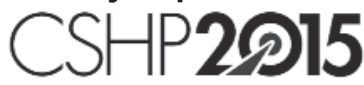 \\ Targeting Excellence in Pharmacy Practice}

Tom E, ${ }^{1}$ Chong $D,{ }^{1}$ Satchu $S,{ }^{1}$ Kertland $H^{1,2}$

${ }^{1}$ St Michael's Hospital, Toronto, ON

${ }^{2}$ Leslie Dan Faculty of Pharmacy, University of Toronto, Toronto, ON

Background: The introduction of computerized prescriber order entry (CPOE) and electronic medication administration records (eMAR) to all non-critical care areas of our hospital occurred as a staggered rollout. Our goal was to ensure a smooth transition throughout the implementation.

Description: The pharmacy department developed and delivered a rollout plan as each of the 13 patient cares area went live.

Action: Early work included development and implementation of order sets, policy and procedures and assessment of pharmacists' daily workflows. Prior to each launch, the unit's pharmacist was engaged to anticipate the shift in medication order review activities, address service-specific issues and identify required supports and scheduling needed during the launch. System training and support to all pharmacists was provided with the first unit launch. For subsequent units review of new service-specific orders and tip sheets were used. Debriefing sessions were held with the pharmacists weekly after each roll out. Learnings from each launch were incorporated into the next unit launch.

Evaluation: Six months after the implementation pharmacists were asked how the rollout could have been improved. Overall, the pharmacists felt the rollout went well particularly as the staggered approach allowed for learnings to be applied to subsequent rollouts. Pharmacists gained experience with computerized orders and with the knowledge of several hospital electronic systems found that they became the unit's "go to" person for questions related to the CPOE/eMAR system. It was thought that physicians should have received more training prior to the launch. Education was desired for topics that were "new" for pharmacists (e.g., assessment and validation of all IV infusion orders).

Implications: Careful and intentional planning led to a seamless rollout from the pharmacy department perspective. Feedback from the pharmacists was incorporated into the rollout plan when CPOE/eMAR was launched in the critical care units.

\section{Patient-Perceived Usefulness and Usability of a Smartphone/Online Application in Type 2 Diabetes Self-Management}

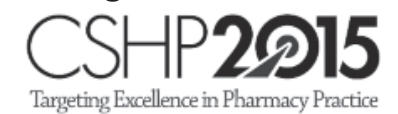

Corey T, Li K, Ho C

\section{School of Pharmacy, University of Waterloo, Waterloo, ON}

Background: Few studies have taken a qualitative approach to determine the potential role of smartphone applications or "apps" in self-management activities of Type 2 Diabetes (T2DM). A qualitative approach may identify pragmatic issues on the use of diseasemanagement apps that may not arise through quantitative analyses.

Objective: This study aimed to evaluate patients' perceived usefulness and usability of a smartphone/online app - Glucose Buddy - in T2DM self-management.

Methods: A convenient sample of 6 participants with T2DM was recruited from a family health team clinic and a community pharmacy. Participants were instructed to use Glucose Buddy on their smartphone or computer. Phone interviews were conducted at 2 and 4 weeks to determine facilitators and barriers of the use of the app, the impact on diabetes self-management, and overall patient-perceived impact on health. A qualitative thematic coding approach was used to identify recurring themes.

Results: Participants had varied opinions regarding the perceived usefulness and usability of the app for T2DM self-management. Some felt that the app helped increase their adherence to glucose monitoring, which led to a greater sense of control over their condition. However, this did not always lead to an increase in other self-management activities such as exercise. The usability of the app also varied among the participants, with "confusion" being identified as a common theme. Lack of intuitive acronyms throughout the app also led to challenges in using and navigating the app.

Conclusions: The impact of smartphone/online application on T2DM self-management appears to be individualized. The tracking features seem to positively impact certain aspects of disease management (e.g., glucose monitoring) but not others (e.g., exercise). Pharmacists should be aware of the practical issues when recommending phone apps to diabetic patients. It is important to individualize app selection to ensure optimal benefits to patient care.

\section{Pompes intelligentes : évaluation pratique des limites de détection}

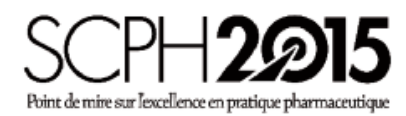

Guérin $A,{ }^{1}$ Lebel $D,{ }^{1}$ Bussières $J F^{1,2}$

${ }^{1}$ Département de pharmacie et Unité de recherche en pratique pharmaceutique, Centre Hospitalier Universitaire Sainte-Justine, Montréal, QC

${ }^{2}$ Faculté de pharmacie, Université de Montréal, Montréal, QC

Justification : L'établissement des limites hautes et infranchissables des pompes intelligentes se fait au sein de chaque établissement de santé en fonction des besoins et des particularités de chaque secteur de soins et à partir d'ouvrages de références.

Objectifs : L’objectif de cette étude était de vérifier au sein du service des soins intensifs d'un hôpital mère enfant, si les limites hautes et infranchissables des pompes intelligentes détectaient les erreurs.

Méthodologie et démarche de l'étude : Une revue de l'utilisation de tous les médicaments perfusés entre le 01 mai 2013 et le 01 mai 2014 a été réalisée à partir du dossier pharmacologique informatisé (GesPharx CGSITI, Québec, Qc)®. L'étude a porté sur tous les patients de l'unité de soins intensifs pédiatriques. Nous avons regardé pour chaque prescription si la dose prescrite dépassait les doses hautes et infranchissables. Afin de tester nos limites, nous avons simulé pour chaque prescription une erreur de 10 fois la dose en multipliant la dose prescrite par 10.

Résultats : L'étude a porté sur 2084 prescriptions et sur 3503 jours d'administration de perfusion continue pour un total de 33 patients. Respectivement 5\% (113/2084) et 2\% (35/2084) des prescriptions étaient au-dessus des limites hautes et infranchissables pour les doses 
prescrites. Pour les erreurs simulées de 10 fois la dose, seulement $24 \%$ $(509 / 2084)$ et $42 \%(875 / 2084)$ auraient été détectées par les limites hautes et infranchissables. Le top 3 des médicaments pour lesquels le nombre de prescriptions réelles est resté le moins détecté par les limites hautes était l'hydromorphone $5 \mathrm{mg} / \mathrm{ml}(\mathrm{n}=13 / 13)$, le sufentanil préparé sur place $(\mathrm{n}=1 / 1)$ et le sufentanil $5 \mathrm{mcg} / \mathrm{ml}(\mathrm{n}=15 / 16)$.

Conclusion : Cette étude démontre la nécessité de réévaluer périodiquement les limites utilisées pour les pompes intelligentes.

\section{Retrospective Review of Emerging Drug Use in a Mother-Child Center in Quebec}

Corny J, ${ }^{1}$ Pelletier E, ${ }^{1,2}$ Lebel D, ${ }^{1}$ Bussières $J F^{1,3}$

${ }^{1}$ Pharmacy Department and Pharmacy Practice Research Unit, CHU

Sainte Justine, Montréal, QC

${ }^{2}$ Pharmacy and Therapeutics Committee, CHU Sainte Justine,

Montréal, QC

${ }^{3}$ Faculty of Pharmacy, Université de Montréal, Montréal, QC

Background: Unapproved and off-label drug use in children is an important issue, with reported prevalences of $1-33 \%$ and $9-34 \%$ respectively. In a teaching hospital, clinicians are frequently confronted with conditions requiring emerging drugs (e.g. drugs without a notice of compliance, off-label drug uses with limited scientific literature and costly drugs (>300\$CAD/dose)).

Objective: To evaluate use of emerging drugs within our hospital.

Methods: We identified retrospectively emerging drugs used between 2013-01-01 and 2014-02-28. Following variables were collected in patient file (initial prescription): age, dates/hours of written intention to use the drug, prescription and first dose administered, written justification (alternatives used/eliminated, efficacy and safety endpoints, delays between intention and prescription, between prescription and first dose administered) and written documentation of consent from parents/patients. Descriptive statistics were performed.

Results: A total of 26 emerging drugs (99 prescriptions, 89 patients) were identified. Top-five therapeutic classes (American Society of Health-System Pharmacists formulary) used were: 44:00-Enzymes (23\% of drugs), 10:00-Antineoplasic agents (15\%), 92:00Miscellaneous therapeutic agents (15\%), 28:00-Central nervous system agents (12\%), 08:00-Anti-infective agents (8\%) and 84:00-Skin and mucous membrane agents $(8 \%)$. Drugs were either unapproved in Canada (42\%), used off-label $(27 \%)$ or costly $(31 \%)$. Median patient's age at initial prescription was 4 years-old [0-18]. Median delay between prescriber's intention and prescription was 2 days [0-333] and was 0 day [0-404] between prescription and first dose administered. Longer delays were associated with outpatient reimbursement authorization processes. Efficacy and safety endpoints were documented in 33\% and $10 \%$ respectively. In $26 \%$ of prescriptions, a side effect was documented. Only $19 \%$ of prescriptions were associated to a documented verbal/written consent.

Conclusion: This study describes 26 emerging drugs involving 99 prescriptions (89 patients) and their current challenges, such as the lack of efficacy and safety endpoints defined to ensure the treatment is effective and safe.

\section{Unlicensed and Off-Label Drug Use in a Mother- Child Tertiary Care Hospital}

Corny J, ${ }^{1}$ Bailey B, ${ }^{2}$ Lebel D, ${ }^{1}$ Bussieres JF',3

${ }^{1}$ Pharmacy Department and Pharmacy Practice Research Unit, CHU

Sainte Justine, Montréal, QC

${ }^{2}$ Emergency Department, CHU Sainte Justine, Montréal, QC

${ }^{3}$ Faculty of Pharmacy, Université de Montréal, Montréal, QC

Background: In the last decades, several governmental initiatives were implemented to increase clinical research and decrease unlicensed and off-label drug use rates in pediatrics. However, it is unclear how much progress was made.

Objective: The objective was to assess the unlicensed and off-label drug uses in a university mother-child hospital.

Methods: We conducted a cross-sectional study in a tertiary university mother-child hospital in Quebec. All active prescriptions during a 24hour period were analyzed. Unlicensed drug use was defined as the use of nonmarketed drugs in Canada or marketed drug with pharmacy compounding. Off-label drug use was defined as the use of marketed drugs in Canada for an unapproved age group, indication, dosing, frequency or route of administration. We also determined if off-label drug uses were associated with strong scientific support, using Lexicomp's ${ }^{\circledR}$ and Micromedex® databases. Number and proportion of unlicensed and off-label drug uses and proportion of off-label drug use with strong scientific support were measured.

Results: A total of 2,698 drug prescriptions was extracted on March 5th, 2014 and included 308 inpatients. Unlicensed drug use rate was $6.8 \%(\mathrm{n}=77$ nonmarketed drugs, $\mathrm{n}=107$ marketed drug with pharmacy compounding) and included 57 different drug substances. Off-label drug use rate was $35.7 \%$ and included 161 substances. Reasons for offlabel drug use were: unapproved age group $(n=436,45.2 \%)$, indication $(n=100,10.4 \%)$, dosing $(n=262,27.2 \%)$, frequency $(n=306,31.7 \%)$ and route of administration $(\mathrm{n}=75,7.8 \%)$. Of all off-label drug use prescriptions, $35.4 \%(n=341)$ were with strong scientific support.

Conclusion: This study allowed us to obtain unlicensed and off-label drug use rates for pediatric inpatients in our center. We found that $6.8 \%$ of prescriptions were unlicensed and $35.7 \%$ were off-label. Of off-label prescriptions, only $35.4 \%$ were associated with a strong scientific support. These results compare with literature results around the world.

\section{Is Pediatric Drug Information the Same for All Children Around the World?}

Corny J, ${ }^{1}$ Lebel D, ${ }^{1}$ Bussières $J F^{1,2}$

${ }^{1}$ Pharmacy Department and Pharmacy Practice Research Unit, CHU

Sainte Justine, Montréal, QC

${ }^{2}$ Faculty of Pharmacy, Université de Montréal, Montréal, QC

Background: Several governmental initiatives were implemented around the world in the last decade to increase clinical research and available data for drugs used in pediatrics. However, pediatric initiatives and requirements concerning the information contained in product monographs can differ between countries depending on the legislation where the drug is marketed.

Description: We compared product monograph requirements for pediatric information between Canada, USA and Europe.

Action: Using the web portals of Health-Canada, Food and Drug Administration (FDA) and European Medicines Agency (EMA), we retrieved product monographs requirements concerning pediatrics. 
Evaluation: According to regulations in Canada, USA and Europe, a pediatric use section is mandatory in the product monograph. If no clinical trials have been performed or if data in pediatrics is insufficient, manufacturers have to indicate that drug should not be used in children. However, depending on the area where the drug is marketed, other requirements for pediatric information in the product monograph are different. In Canada, additional requirements by Health-Canada include age, pediatric dosing, pharmacology and pharmacokinetics. Additionally, manufacturers have to determine if special drug monitoring has to be performed in children. In USA, FDA requires the same information, as well as pediatric precautions, warnings, contraindications and side effects. FDA is also the only agency requiring the mention of inactive ingredients potentially dangerous for a specific subpopulation (e.g. neonates). In Europe, additional requirements by EMA includes pediatric dosing, pharmacology, precautions, side effects, interactions with other drugs or other type of interaction and overdose management.

Implications: This comparison of product monographs requirements for pediatrics in Canada, USA and Europe showed that governmental initiatives didn't have the same impact on available data for pediatrics. This can lead to misinformation of clinicians who are confronted to different monograph and profile of drugs used in pediatrics.

\section{Démarche pour la mise à niveau d'un secteur de soins pharmaceutiques : le cas de la pédiatrie}

Leroux $A,{ }^{1}$ Guérin $A,{ }^{1}$ Bédard $P,{ }^{1}$ Lebel $D,{ }^{I}$ Bussières JF $F^{1,2}$

${ }^{I}$ Département de pharmacie et Unité de recherche en pratique

pharmaceutique, Centre Hospitalier Universitaire Sainte-Justine,

Montréal, $Q C$

${ }^{2}$ Faculté de pharmacie, Université de Montréal, Montréal, QC

Justification : Le concept de pratique fondée sur les preuves est peu à peu intégré en pharmacie.

Objectif : Mettre à jour le niveau de pratique utilisé en soins pharmaceutiques pédiatriques à partir de données probantes.

Méthodologie et démarche : Il s'agit d'une étude descriptive avec revue documentaire menée dans un centre hospitalier universitaire mère-enfant canadien. La démarche de mise à niveau proposée comporte deux étapes soit une revue de la documentation des articles publiés en français et anglais entre 2009 et 2014 et une description de la mise à jour du niveau de pratique.

Résultats : Des 236 articles recensés, 14 ont été retenus. Nous avons recensé un article reposant sur des données de très bonne qualité (A), deux articles reposant sur des données de qualité acceptable (B), un article reposant sur des données de qualité insuffisante et 10 articles décrivant le rôle et les retombées du pharmacien sans analyse statistique. La mise à jour envisagée du secteur de pratique inclut une rencontre des parents de tous les patients en début d'hospitalisation, la prescription des modifications d'antibiothérapie suite aux dosages sériques, la déclaration à Santé Canada de tous les effets indésirables, la présentation d'un club de lecture au sein du département de pédiatrie, la certification de pharmaciens au Board Pharmacy Speciality pédiatrique, la vérification systématique des ordonnances de départ, et l'identification et la documentation au dossier de tous les médicaments en la possession des patients.

Conclusion : Cette étude descriptive met en évidence le rôle du pharmacien en pédiatrie dans un centre hospitalier de soins universitaire mère enfant. Il existe peu de données sur le rôle du pharmacien pour cette activité; notre approche fondée sur les preuves et sur la réévaluation de nos activités a toutefois permis d'identifier une quinzaine de changements et d'améliorations à nos pratiques actuelles.

\section{Conformité des ordonnances à la règle d'émission des médicaments : étude pilote au sein d'un $\mathrm{CHU}$ mère-enfant}

Ballandras $C,{ }^{1}$ Lebel D, ${ }^{1}$ Atkinson $S,{ }^{1}$ Bussières $J F^{1,2}$

${ }^{1}$ Département de pharmacie et Unité de recherche en pratique pharmaceutique, Centre Hospitalier Universitaire Sainte-Justine, Montréal, QC

${ }^{2}$ Faculté de pharmacie, Université de Montréal, Montréal, QC

Contexte : En vertu du cadre juridique en vigueur, le chef du département de pharmacie d'un établissement de santé doit établir une règle d'émission des ordonnances de médicaments encadrant notamment la rédaction des ordonnances et les prescripteurs autorisés.

Objectif : Évaluer la conformité des ordonnances à la règle d'émission des médicaments au sein d'un CHU mère-enfant.

Méthodologie : Au sein de notre établissement, les ordonnances de médicaments sont manuscrites ou électroniques selon les unités de soins. Une grille d'audit comportant 22 critères a été créée. Neuf critères portaient sur la conformité des feuilles d'ordonnances (p.ex. présence de l'adressographe) et 13 critères portaient sur la conformité du contenu des ordonnances de médicaments (p.ex. présence de la dose). L'audit a été réalisé sur l'ensemble des ordonnances numérisées reçues à la pharmacie le 17 juin 2014.

Résultats : Un total de 359 feuilles d'ordonnances correspondant à 746 ordonnances a été analysé. Le taux global de conformité des feuilles d'ordonnances était de 19,5\%(70/359). Le taux de conformité était supérieur à $90 \%$ pour $5 / 9$ critères (p.ex. présence de la date de naissance). Cependant, le poids n'était présent que dans $64,1 \%(230 / 359)$ des cas et le statut allergique dans seulement $24,5 \%(88 / 359)$ des cas. Le taux global de conformité du contenu des ordonnances était de 23,9\%(178/746). Le taux de conformité était supérieur à $90 \%$ pour $10 / 13$ critères (p.ex. présence de la date). Cependant, l'heure de prescription n'était présente que dans $67 \%(500 / 746)$ des cas et la mention du nom générique dans $79,2 \%(591 / 746)$ des cas.

Conclusion : Moins du quart des feuilles d'ordonnances et des ordonnances se conformaient entièrement à la règle d'émission des ordonnances. Il est difficile pour des prescripteurs de se plier à toutes ces règles; le recours à la prescription électronique est envisagé au sein de notre établissement pour pallier à ces écarts.

\section{Audit of the Labelling of Hazardous Drugs in the Canadian Market

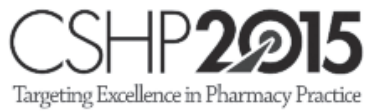 \\ Janes $A,{ }^{1}$ Bérard $C,{ }^{1}$ Bussières $J F^{1,2}$ \\ ${ }^{1}$ Pharmacy Department and Pharmacy Practice Research Unit, CHU Sainte-Justine, Montréal, QC \\ ${ }^{2}$ Faculty of Pharmacy, Université de Montréal, Montréal, QC}

Background: There are no guidelines regarding the commercial labelling of hazardous drugs in Canada. However, it is essential that hazardous drugs can be clearly and easily identified throughout the druguse process in order to prevent occupational exposure for health professionals.

Objective: To describe the current state of the labelling of hazardous drugs in Canada.

Methods: The list of hazardous drugs issued by the National Institute for Occupational Safety and Health (NIOSH) in 2012 was used. Outer and inner labels of hazardous drugs from one Canadian wholesaler were 
analysed. For each label, we evaluated the presence of symbols or mentions about the existence of a risk. We defined a label as compliant if at least 1 of the 3 following criteria was present: cytotoxic symbol, "cytotoxic/toxic" mentions or safe handling precaution mentions. We calculated the proportion of compliant labels.

Results: A total of 336 drugs were analysed on August 21 $1^{\text {st }}, 2014$, out of which 42\% (141/336) were antineoplastic drugs. Of these 336 products, 383 labels were assessed (i.e.18 outer packaging when available, 240 outer labels and 125 inner labels). Of all the labels analyzed, 80\% (305/383) of the labels were non-compliant (Table 1). Among the $20 \%$ compliant labels, $72 \%$ (56/78) corresponded to antineoplastic drugs.

Table 1. Proportion of compliant labels of hazardous drugs

\begin{tabular}{|c|c|c|c|}
\hline Drug type & Label types & $\begin{array}{c}\text { Compliant } \\
\mathrm{N}(\%)\end{array}$ & $\begin{array}{c}\text { Non compliant } \\
\mathrm{N}(\%)\end{array}$ \\
\hline \multirow{4}{*}{$\begin{array}{l}\text { All hazardous drugs } \\
(\mathrm{n}=336)\end{array}$} & Outer packaging $(\mathrm{n}=18)$ & $7(39 \%)$ & $11(61 \%)$ \\
\hline & Outer label $(n=240)$ & $55(23 \%)$ & $185(77 \%)$ \\
\hline & Inner label $(\mathrm{n}=125)$ & $16(13 \%)$ & $109(87 \%)$ \\
\hline & Total $(n=383)$ & $78(20 \%)$ & $305(80 \%)$ \\
\hline \multirow{4}{*}{$\begin{array}{l}\text { Antineoplastic } \\
\text { hazardous drugs }(n=141)\end{array}$} & Outer packaging $(\mathrm{n}=12)$ & $7(58 \%)$ & $5(42 \%)$ \\
\hline & Outer label $(\mathrm{n}=125)$ & $38(30 \%)$ & $87(70 \%)$ \\
\hline & Inner label $(\mathrm{n}=37)$ & $11(30 \%)$ & $26(70 \%)$ \\
\hline & Total $(\mathrm{n}=174)$ & $56(32 \%)$ & $118(68 \%)$ \\
\hline \multirow{4}{*}{$\begin{array}{l}\text { Non-antineoplastic } \\
\text { hazardous drugs } \\
(\mathrm{n}=195)\end{array}$} & Outer packaging $(n=6)$ & $0(0 \%)$ & $6(100 \%)$ \\
\hline & Outer label $(\mathrm{n}=115)$ & $17(15 \%)$ & $98(85 \%)$ \\
\hline & Inner label $(\mathrm{n}=88)$ & $5(6 \%)$ & $83(94 \%)$ \\
\hline & Total $(\mathrm{n}=209)$ & $22(11 \%)$ & $187(89 \%)$ \\
\hline
\end{tabular}

Conclusion: Less than a quarter of hazardous drugs labels were considered compliant in clearly identifying the risk of occupational exposure. Health Canada should define criterias required to clearly identify hazardous drugs.

\section{Tolerability of Darunavir/Ritonavir, Tenofovir/Emtricitabine for Human Immunodeficiency Virus Postexposure Prophylaxis}

Hutton L, ${ }^{1}$ MacPherson $P^{2,3}$ Corace $K^{4}{ }^{4}$ Leach T, ${ }^{5}$, Giguère P ${ }^{1,6}$ ${ }^{1}$ Department of Pharmacy, The Ottawa Hospital, Ottawa, ON ${ }^{2}$ Division of Infectious Diseases, The Ottawa Hospital, Ottawa, ON ${ }^{3}$ Faculty of Medicine, University of Ottawa, Ottawa, ON, ${ }^{4}$ Department of Psychology, The Ottawa Hospital, Ottawa, ON ${ }^{5}$ Department of Emergency Medicine, Sexual Assault and Partner Abuse Care Program, The Ottawa Hospital, Ottawa, ON

${ }^{6}$ The Ottawa Hospital Research Institute, Ottawa, ON

Background : Postexposure prophylaxis (PEP) for HIV has improved in tolerability and dosing complexity over the past two decades. In March 2013, the study site changed its PEP therapy to darunavir/ ritonavir (DRVr) and tenofovir/emtricitabine (TDF/FTC). To date, no studies have assessed the tolerability of this medication combination as PEP.

Objectives: The primary objective of this study was to assess tolerability of DRVr + TDF/FTC. The secondary objectives were to explore adherence, discontinuation rates, seroconversion and quality of life associated with DRVr + TDF/FTC treatment as a PEP regimen.

Methods: Patients receiving DRVr + TDF/FTC were asked to voluntarily complete three self-report questionnaires measuring common adverse effects, adherence and quality of life during the first and fourth (last) weeks of treatment. Participants were recruited from the study site. The results were and reported analyzed using measures of central tendency and descriptive statistics (SPSS v20).
Results: Fifty-one subjects were enrolled in the study from April to November 2013. Sixty percent were female with a mean age of 34 years. $\mathrm{DRVr}+\mathrm{TDF} / \mathrm{FTC}$ were discontinued in 24 subjects (47\%), 6 (12\%) were considered treatment-related discontinuations. Commonly reported moderate side effects during weeks one and four were tiredness/fatigue $(61 \%, 36 \%)$, nausea $(56 \%, 4 \%)$ and loss of appetite $(47 \%$, $40 \%$ ). Severity was described as at least moderate in $60 \%$ and $20 \%$ at weeks 1 and 4 respectively. Sign test indicated that the frequency and severity of side effects significantly improved over the course of PEP treatment $(\mathrm{p}<0.05)$. Mean adherence was above $95 \%$ at all times. Compared to subjects seen at the infectious diseases clinic, subjects at the second site reported worse adherence at week 1 but similar at week 4. No HIV seroconversion occurred during the study.

Conclusion: Once daily DRVr + TDF/FTC as PEP is convenient, well tolerated, and associated with few treatment-related discontinuations.

\section{Prophylaxis of Post-traumatic Infectious Endophthalmitis: Probability of Fluoroquinolone Success Using Monte Carlo Simulations}

Peragine $C,{ }^{2}$ Palmay L, ${ }^{1}$ Walker SAN, ${ }^{1,2,3}$ Walker $S E^{1,2}$

${ }^{1}$ Department of Pharmacy, Sunnybrook Health Sciences Centre, Toronto, $O N$

${ }^{2}$ Leslie Dan Faculty of Pharmacy, University of Toronto, Toronto, ON

${ }^{3}$ Division of Infectious Diseases, Sunnybrook Health Sciences Centre, Toronto, ON

Background : Infectious endophthalmitis is a serious complication of open-globe injury. One case series reported that moxifloxacin $800 \mathrm{mg}$ PO Q12H can deliver intraocular concentrations that exceeded the $\mathrm{MIC}_{90}$ of common pathogens, but equivalent studies using other fluoroquinolones have not been conducted.

Objective: To determine pharmacokinetic (PK) and pharmacodynamic (PD) properties of ciprofloxacin, levofloxacin, and moxifloxacin to model the likelihood of microbiologic success and compare the efficacy of 9 potential recommended dosing regimens.

Methods: A literature search determined the weighted mean of all PK variables required to generate an oral concentration time profile. Steady state peak plasma concentrations of the unbound drug $\left(\mathrm{fC}_{\max }\right)$ and the unbound 24-hour plasma AUC (fAUC ${ }_{24 h}$ ) were generated. The free concentration was used, assuming that free-drug concentrations in plasma approximate the vitreous humor concentrations in the eye. Pathogen-specific fAUC $24 \mathrm{~h}$ :MIC breakpoints were used to determine microbiologic success. A Monte Carlo simulation with 1 million iterations per regimen was used to determine the proportion of the simulated population that exceeded the pathogen-specific fAUC $24 \mathrm{~h}$ :MIC breakpoints. A $10 \%$ difference in success was judged clinically significant.

Results: Nine fluoroquinolone regimens were assessed for each pathogen. Using the $\mathrm{fAUC}_{24 \mathrm{~h}}$ :MIC endpoint, the highest chance of overall prophylactic success was achieved using a regimen of levofloxacin $1000 \mathrm{mg}$ daily ( $85.6 \%$ success rate). $400 \mathrm{mg}$ moxifloxacin BID was a close second achieving success in $81.2 \%$ of cases. This difference is not clinically significant. Both levofloxacin (500mg daily) and moxifloxacin (400mg daily) achieved microbiological success in more than $75 \%$ of cases and performed better than maximal doses of ciprofloxacin $(750 \mathrm{mg}$ BID) achieving success in $68.4 \%$ of cases.

Conclusion: No safety data exits for $400 \mathrm{mg}$ BID of moxifloxacin. Simulation suggests that prophylactic use of $1000 \mathrm{mg}$ of levofloxacin po daily (a Health Canada approved dose) has the highest probability of attaining PK/PD targets and microbiological success for preventing post-traumatic endophthalmitis. 


\section{Natural Health Product Use in Patients with Rheumatological Conditions}

Dissanayake $T,{ }^{1}$ Hagen $K,{ }^{2} \mathrm{Katz} S,{ }^{1}$ Hall ${ }^{2}$

${ }^{1}$ Division of Rheumatology, University of Alberta, Edmonton, $A B$

${ }^{2}$ Faculty of Pharmacy and Pharmaceutical Sciences, University of Alberta, Edmonton, $A B$

Background : Natural health products (NHPs) are naturally occurring substances available without a prescription, frequently used to restore or maintain good health, often in addition to or in place of conventional therapy. Previous literature has shown that the prevalence of NHP use is higher in patients with rheumatological conditions compared to the general population. However, NHP use is frequently under-reported and thus represents a common but often overlooked aspect of the patient medication history.

Objective: The aim of this study was to describe the population-based rates and patterns of NHP use in patients with rheumatologic conditions.

Methods: We conducted an observational cross-sectional survey of patients with rheumatological conditions in Edmonton, Alberta. Patients attending the 2 largest rheumatology clinics over an 8-week period were invited to participate. Response items included self-reported NHP use, medical conditions and medications, as well as demographic data. Data were analyzed using descriptive statistics and included an inflammatory arthritis subgroup.

Results: Of the 1063 patients who completed the survey (response rate, $36 \%$ ), $60 \%$ reported using of one or more NHPs, with a mean of 2.9 products. When excluding vitamins and minerals, the prevalence decreased to $40 \%$ and the mean number of NHPs to 1.8 . There were no differences between the entire cohort and the IA subgroup. A variety of NHPs were reported, with management of joint health being the most common indication. The majority of patients stated that they would not discontinue conventional prescribed medication in favour of NHPs. Almost $65 \%$ of NHP users stated they informed their physicians of NHP use, however, only $20 \%$ informed their pharmacist and even fewer informed other health care professionals. A minority of patients noted any benefit or adverse effect from therapy.

Conclusion: Our study confirmed the frequent use, but underreporting, of NHPs by patients with rheumatologic conditions.

\section{Multidisciplinary Review Process Demonstrates the Need for Early Pharmacist Notification with Treatment Intervention Benefits in Clostridium difficile Infection (CDI)

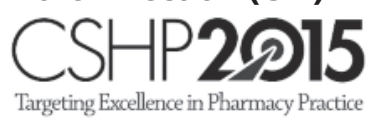

Popovski Z, Dhami R, Creamer L, Jansen S, Elsayed S, Nancekevill B, Newman A, Bossy J, Vandersluis $C$

London Health Sciences Centre, London, ON

Background : A multidisciplinary review process of nosocomial CDI revealed numerous medication related improvement opportunities. In addition to important infection control interventions, pharmacists' scope of practice was identified as critical to addressing medication-related issues in the treatment of CDI.

Description: Antimicrobial stewardship pharmacists reviewed nosocomial CDI cases for medication related issues and made recommendations to reduce the risk and/or improve treatment of CDI. Recommendations included broad antimicrobial stewardship initiatives which will serve in planning priorities. In addition, discordance with evidence based guidelines for treatment of CDI revealed a need for early notification of pharmacists to address treatment issues.

Action: A new process for direct notification of all pharmacists of CDI by the Microbiology Lab was developed to ensure prompt treatment according to guidelines. Interventions include matching disease severity stratification to treatment regimen, reducing time to initial dose as well as ensuring reassessment of systemic antimicrobials and proton pump inhibitors.

Evaluation: Monthly audits of pharmacists' interventions in all CDI cases ranged from $42 \%$ to $100 \%$. Pharmacists report interventions are required in $>90 \%$ of CDI cases and acceptance of $>90 \%$ of medication related recommendations. Planned process improvements include ongoing education and electronic documentation of interventions.

Implications: Our multidisciplinary review process provided valuable education about the pharmacists' role in prevention and treatment of CDI. Including pharmacists in the initial notification of CDI by the Microbiology lab ensures prompt appropriate therapy and addresses numerous medication related issues identified in a multidisciplinary review process. Clinical and economic outcomes will also be measured before and after the new process. Our intervention was submitted as a corporate quality improvement project (QIP) and the important role of pharmacists' early intervention has been well established.

\section{Pharmacist's Perception of the Implementation of Computerized Prescriber Order Entry (CPOE) on Their Practice}

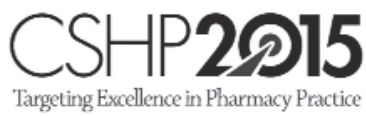

Kertland $H^{1,2}$ Tom $E^{\prime}$

${ }^{1}$ Department of Pharmacy, St Michael's Hospital, Toronto, ON ${ }^{2}$ Leslie Dan Faculty of Pharmacy, University of Toronto, Toronto, ON

Background : CPOE is advocated as a patient safety initiative. The impact of this technology has been measured by metrics such as reduced medication turnaround time and decreased inappropriate antibiotic choices. However, how it impacts a pharmacist's practice is not known.

Objective: We wished to determine how this technology impacted a pharmacist's practice.

Methods: We conducted a qualitative study inviting pharmacists who worked a minimum of six months prior to and following the implementation of CPOE to participate. One-on-one interviews were conducted using a semi-structured guide by a trained interviewer. Two investigators analyzed the verbatim transcripts to identify themes. The analysis was validated with a group of eligible pharmacists

Results: Fourteen pharmacists were interviewed and all thought it had a positive impact on their practice. Pharmacists perceived that $\mathrm{CPOE}$ had the greatest impact on their role in the medication system, direct patient care and interdisciplinary team collaboration. For the first two roles, major themes were improved efficiency (e.g., prioritization of orders, timely medication order review, quicker resolution of problem orders, complete medication profile was available for patient assessment) and safety (easier to determine appropriate timing of next dose, no illegible writing, increased time to resolve complex problems). Interdisciplinary team communication, particularly order clarification with physicians, was facilitated by the timeliness of order review. The use of technology revealed new safety concerns that emphasized the essential role that a pharmacist has to ensure patient safety.

Conclusion: Overall, pharmacists perceived that the introduction of CPOE had a positive impact on their practice. It permitted a more 
efficient assessment of medication and patient information providing additional time to identify and resolve drug therapy problems. New types of safety concerns were detected which needed to be addressed.

\section{Anticoagulation and Antiplatelet Patterns in Patients with Atrial Fibrillation Post-percutaneous Coronary Intervention}

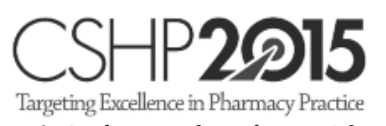

Woods E, ${ }^{1}$ Ackman $M,{ }^{1}$ Graham $M,{ }^{2}$ Koshman $S,{ }^{2}$ Boswell $R,{ }^{1}$ Barry $A^{1}$

${ }^{1}$ Pharmacy Services, Alberta Health Services, Edmonton, $A B$

${ }^{2}$ Division of Cardiology, University of Alberta, Edmonton, $A B$

Background : Guidelines recommend triple antithrombotic therapy (TAT), defined as acetylsalicylic acid (ASA), clopidogrel, and warfarin, in patients with non-valvular atrial fibrillation (NVAF) who undergo percutaneous coronary intervention with stenting (PCI).

Objective: The objective of this study was to characterize the real-world use of anticoagulant and antiplatelet therapy at discharge in patients with NVAF post-PCI, and identify determinants of the most commonly utilized regimens.

Methods: A retrospective chart review was conducted at the Mazankowski Alberta Heart Institute from January 2011 to December 2013. Adult inpatients with NVAF undergoing PCI were included. The primary outcome was the proportion of patients discharged on TAT.

Results: The cohort consisted of 71 patients (median age 75 years, $73 \%$ male), with median CHADS2 and HASBLED scores of 2 and 3, respectively. Nine patients (12\%) had a previous gastrointestinal (GI) bleed. At discharge, $42 \%$ received TAT and 38\% received clopidogrel and ASA (dual antiplatelet therapy or DAT). Of those who received TAT, $53 \%$ had a recommended duration of one month followed by warfarin and ASA indefinitely, whereas 23\% had a recommended TAT duration of one year. DAT was recommended for one year in $37 \%$ and six months in $19 \%$. Novel oral anticoagulants with antiplatelet drugs were prescribed in $8 \%$ of patients, while $7 \%$ received ticagrelor and ASA and $1.4 \%$ received warfarin and clopidogrel. No patients with a previous gastrointestinal (GI) bleed received TAT. In a multivariate logistic regression analysis, female sex and gastroesophageal reflux disease were independent predictors for use of DAT.

Conclusion: Despite a guideline-based indication, less than half of eligible patients received TAT, and 20\% received non-evidence based combinations including novel oral anticoagulants and ticagrelor. Other than consideration of GI bleed, the rationale for using DAT in place of TAT was unclear. Further studies are needed to understand variance from guideline-based therapy.

\section{A Pharmacy Practice Residency Program at a Paediatric Quaternary Hospital: Program Review and Evaluation}

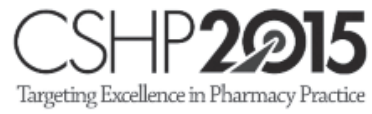

Chung E, ${ }^{1,2}$ Zao J, ${ }^{1,2}$ Seto $W^{1,2}$ Bjelajac Mejia $A^{1,2}$

${ }^{1}$ The Hospital for Sick Children, Toronto, ON

${ }^{2}$ Leslie Dan Faculty of Pharmacy, Toronto, ON
Background : A pharmacy practice residency is defined by the Canadian Pharmacy Residency Board (CPRB) as an organized, directed, and accredited program that focuses on developing the residents' competencies in direct patient care, pharmacy operations, project management, personal practice aspects of pharmacy practice, and leadership roles.

Description: Two pharmacy residency positions that focus on paediatric pharmacy practice have been offered annually since 1984 at a single site in Canada. It is a 12-month general residency program that is accredited by CPRB and is affiliated with the University of Toronto. No published work has reviewed the development or examined the outcomes of the pharmacy residency program. Therefore, our purpose is to review the evolution of this program and determine its impact on the institution.

Action: Data was extracted from CPRB accreditation documents, preceptor meeting minutes, residency advisory committee meeting minutes, past and current residency coordinators, residency program files, the residency program outline, residency research meeting minutes, and the Residency Matching Service (RMS) rank lists.

Evaluation: Recent milestones of the paediatric pharmacy residency program include an expansion of rotations, the addition of teaching opportunities, the development of structured assessment tools, a revision of the recruitment process, and an enhancement of the residency experience. Since 1984, there have been 54 program graduates. Ninety-two percent of candidates who were matched to the program were ranked top 3 by the hospital since the implementation of RMS in 2003. Accomplishments of the graduates include 15 local and national awards, and 27 publications in peer-reviewed journals. Seventy-three percent of graduates are currently employed at the institution.

Implications: This paediatric pharmacy residency program has produced accomplished clinical pharmacists with distinguished awards and significant contributions to paediatric practice and the literature. It has also seen a significant retention of program graduates competent in providing paediatric care.

\section{Patient Satisfaction with Chronic HIV Care Provided through an Innovative Pharmacist and Nurse- Managed Clinic or a Multidisciplinary Clinic

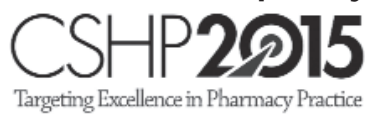

Kielly J, ${ }^{1,2}$ Kelly DV ${ }^{1,2}$ Biggin J, ${ }^{1}$ Asghari $S^{3}$

${ }^{1}$ School of Pharmacy, Memorial University of Newfoundland, St. John's, NL ${ }^{2}$ Eastern Health, St. John's, NL

${ }^{3}$ Faculty of Medicine, Memorial University of Newfoundland, St .John's, NL

Background : Utilizing health professionals to their full scope supports provision of effective and efficient care. Pharmacist and nurse-led clinics are an established model for many chronic diseases but not yet for HIV. At our centre all HIV+ patients are seen by a multidisciplinary team (MDC: physician, nurse, pharmacist and social worker) at least yearly but some attend an HIV-specialist pharmacist/nurse clinic (PNC) for alternate biannual visits.

Objective: To assess patient satisfaction with chronic HIV care received through MDC and PNC.

Methods: A telephone survey was administered to consenting, eligible patients (English-speaking adults who attended the MDC or PNC between January-July 2014). Survey questions came from Patient Assessment of Chronic Illness Care (PACIC) which measured overall satisfaction, and Patient Satisfaction Survey for HIV Ambulatory Care (PSS-HIV), which assessed access to care, medical visits, and quality of care. The survey was pretested for face and content validity. Descriptive 
statistics were used to describe patient characteristics and satisfaction scores. T-test compared satisfaction scores between PNC and MDC. Logistic regression examined associations between independent variables (e.g. demographics) and dependent variables (e.g. satisfaction with care).

Results: Response rate was 51.6\% (49/95 patients). Overall satisfaction was high (mean PACIC score 3.14 out of 5), and did not differ between PNC and MDC (2.96 vs. 3.19, p=0.42). Satisfaction on domains assessed by PSS-HIV are described in the table. Only geographic location was predictive of satisfaction on multivariate analysis, with rural respondents indicating higher satisfaction $(\mathrm{p}=0.05)$.

Percentage of respondents* who agreed with selected satisfaction statements (from PSS-HIV survey)

\begin{tabular}{ll}
\hline Access to Care & \\
Appointment availability met my needs & $35 / 40(88 \%)$ \\
Off hours care was available when needed & $17 / 24(71 \%)$ \\
I could access care via phone or email to discuss medical questions & $38 / 42(90 \%)$ \\
\hline $\begin{array}{l}\text { Medical Visits } \\
\text { Providers asked for my input in deciding treatment plans }\end{array}$ & $42 / 47(89 \%)$ \\
$\begin{array}{l}\text { Providers explained medication side effects in a way I could understand } \\
\text { Providers suggested ways to help remember to take my HIV medications }\end{array}$ & $47 / 47(100 \%)$ \\
Overall Quality of Care & \\
I would rate my providers knowledge of the newest developments & $39 / 45(87 \%)$ \\
in HIV medical standards as excellent/very good & \\
Most frequently selected descriptors used to reflect how respondents & \\
felt about care received through clinic: & \\
Caring & $49 / 49(100 \%)$ \\
Friendly & $49 / 49(100 \%)$ \\
Respectful & $48 / 49(98 \%)$ \\
Understanding & $48 / 49(98 \%)$ \\
\hline
\end{tabular}

${ }^{*}$ Not all respondents answered all questions

Conclusion: Patients are satisfied with both clinics, supporting PNC as an innovative model for chronic HIV care. Comparison of outcomes between clinics is needed to ensure high quality care for all patients.

\section{Use of Therapeutic Drug Monitoring to Improve Paediatric Clinical Pharmacy Service at a Tertiary Hospital}

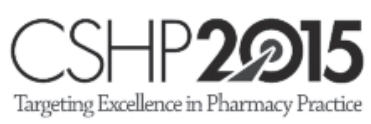

Lim SH, ${ }^{1}$ Chen $W^{1}$ Seto $W^{1,2,3}$

${ }^{1}$ Leslie Dan Faculty of Pharmacy, University of Toronto, ON

${ }^{2}$ Department of Pharmacy, The Hospital for Sick Children, Toronto, ON

${ }^{3}$ Child Health Evaluative Sciences, The Hospital for Sick Children,

Toronto, $O N$

Background : Therapeutic drug monitoring (TDM) of certain medications is essential in the maintenance of serum drug concentrations within the desired therapeutic range, above which toxicity occurs and below which ineffective therapy occurs. As paediatric patients undergo physiological changes that leads to different pharmacokinetic parameters compared to adults, a TDM service was initiated at a tertiary hospital. Since then, TDM service has expanded to align with the hospital's strategic directions: create a culture of service of excellence, optimize patient safety and foster clinical research excellence.

Description: TDM service expansion initiatives were implemented in 3 domains: clinical patient care, continuous quality improvement and clinical pharmacy research.

Action: Clinical patient care improvements were identified through TDM based initiatives. Annual review of TDM results and clinical pharmacist TDM recommendations in ensuring continuous quality improvement and patient safety were analyzed. Evidence to improve medication dosing in paediatric patients was generated from TDM research studies.
Evaluation: TDM certification program, development of new assays, staff TDM education and new order sets were implemented to improve clinical patient care. Review of TDM results and pharmacist TDM recommendations identified information gaps in current paediatric dosing regimens. TDM research studies have led to practice changes such as the hospital-wide implementation of once-daily dosing aminoglycosides.

Implications: Through the application of clinical pharmacy research methodology and quality improvement process, initiatives were implemented to improve paediatric clinical pharmacy service through TDM.

\section{Guideline for the Prevention of Breakthrough and Treatment of Refractory Chemotherapy-Induced Nausea and Vomiting in Pediatric Cancer Patients}
Flank J, ${ }^{1,4}$ Robinson PD, ${ }^{5}$ Holdsworth $M,{ }^{6}$ Portwine $C,{ }^{7}$ Gibson $P^{8}$ Phillips $R,{ }^{10,11}$ O'Shaughnessy E, ${ }^{12}$ Maan $C,{ }^{9}$ Stefin $N,{ }^{13}$ Sung $L,{ }^{2,3}$ Dupuis $L L^{1,3,4}$
${ }^{1}$ Department of Pharmacy, The Hospital for Sick Children, Toronto, ON ${ }^{2}$ Department of Haematology/Oncology, The Hospital for Sick Children, Toronto, ON
${ }^{3}$ Research Institute, The Hospital for Sick Children, Toronto, ON
${ }^{4}$ Leslie Dan Faculty of Pharmacy, University of Toronto, Toronto, ON
${ }^{5}$ Pediatric Oncology Group of Ontario, Toronto, ON
${ }^{6}$ Department of Pharmacy Practice and Administrative Sciences,
University of New Mexico, Albuquerque, NM, USA
${ }^{7}$ Department of Pediatrics, McMaster University, Hamilton, ON
${ }^{8}$ Department of Paediatric Oncology/Haematology, Children's Hospital
at London Health Sciences Centre, London, ON
${ }^{9}$ Department of Psychology, Children's Hospital at London Health
Sciences Centre, London, ON
${ }^{10}$ Department of Oncology, Leeds Children's Hospital, Leeds,
West Yorkshire, UK
${ }^{11}$ University of York, Heslington, York, UK
${ }^{12}$ Department of Nursing, Children's Hospital of Eastern Ontario,
Ottawa, $O N$
${ }^{13}$ McMaster Children's Hospital, Hamilton, ON

Background : Control of chemotherapy-induced nausea and vomiting (CINV) in children receiving chemotherapy remains sub-optimal. The best approach to manage breakthrough CINV is uncertain.

Objectives: To provide clinicians with an evidence-based approach to treat breakthrough CINV and prevent refractory CINV in children and to identify evidence gaps in this field.

Methods: An inter-professional, international panel of experts was convened. A systematic search for existing guidelines on this topic was undertaken. Since no guideline was identified for adaptation or endorsement as assessed using the Appraisal of Guidelines Research and Evaluation II instrument, systematic reviews of primary studies evaluating interventions for breakthrough and/or refractory CINV in oncology patients of any age and the general safety of such interventions in children were undertaken. Recommendations were developed through review of the evidence and differences in interpretation among panel members were resolved by consensus. The GRADE approach was used to describe the quality of evidence and strength of recommendations.

Results: A total of 4335 references were identified by the search strategy. After screening titles and abstracts, 109 papers were retrieved in full and 61 satisfied the eligibility criteria. Recommendations made include: ensuring guideline-consistent acute antiemetic prophylaxis is provided, upgrading the antiemetic prophylaxis a patient is receiving to that suggested for a chemotherapy regimen of a higher emetogenicity ranking, and the use of additional antiemetic agents, such as olanzapine. 
Evidence gaps identified include: the outcomes of CINV prophylaxis escalation in children experiencing breakthrough or refractory CINV and the optimal pediatric dose of additional antiemetic agents such as olanzapine.

Conclusions: This guideline provides clinicians with evidence-based recommendations intended to improve CINV control and quality of life in pediatric cancer patients. Prospective evaluation of the contribution of this guideline to CINV control and trials to address the significant evidence gaps identified are needed.

\section{Impact of Pharmacist Interventions on Outpatient Parenteral Antimicrobial Therapy Information Transfer at Hospital Discharge}

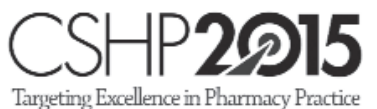

Liu JN, ${ }^{1}$ McKenna $S,{ }^{1}$ Guo L, ${ }^{1}$ Hopman $W^{2}$

${ }^{1}$ Department of Pharmacy Services, Kingston General Hospital, Kingston, ON

${ }^{2}$ Department of Public Health Sciences, Faculty of Medicine, Queen's University, Kingston, $O N$

Background : Successful outpatient parenteral antimicrobial therapy (OPAT) after hospital discharge depends on effective information transfer. However, essential details to be communicated to primary care providers remain to be standardized.

Description: Pharmacists can contribute to successful OPAT through antimicrobial stewardship and patient education.

Action: An intervention set was developed for Antimicrobial Stewardship pharmacists to systematically assess and document an optimal OPAT regimen and monitoring plan for physicians to include in the electronic hospital discharge summary (eDS).

Evaluation: This prospective, double-armed cohort study evaluated the eDS for adult patients who received either usual care alone $(n=62)$, or systematic pharmacist-conducted assessment and documentation (SPCAD) of antimicrobial therapy in addition to usual care $(\mathrm{n}=20)$, prior to hospital discharge with OPAT. The primary outcome was the proportion of eDSs containing all six predefined OPAT details: antimicrobial name, regimen, duration, indication, laboratory monitoring, and most-responsible physician(s). This outcome was not significantly changed by the SPCAD process compared with usual care alone $(30.0 \%$ versus $17.7 \%, \mathrm{P}=0.24)$. The groups did not differ significantly in the secondary outcomes, which were the proportion of eDSs containing any combination of the OPAT details and early rehospitalisation rates among a geographically accessible subgroup. All 17 potential interventions were conducted for at least $60 \%$ of patients, supporting their future application. Timely identification of patients was identified as a challenge.

Implications: To our knowledge, this was the first study to assess, and attempt to improve with pharmacist interventions, the completeness of OPAT information transfer in adult patients. The pre-discharge pharmacist interventions appeared to be practical. However, this study lacked statistical power to conclude their impact on the completeness of OPAT information transfer. Further investigation on the effects of pharmacist activities at hospital discharge on OPAT is warranted given the importance of communication at this care transition.

\section{Survey of Healthcare Professionals on the Role of Pharmacists in an Outpatient HIV Clinic Setting $\overbrace{\text { Targeting Excellence in Pharmacy Practice }}$}

Wong A, ${ }^{1}$ Giguère P, Robinson L, ${ }^{3}$ Martel D, ${ }^{4}$ Toy J, ${ }^{5}$ Sulz L, ${ }^{6}$

Sheehan $N,{ }^{1}$ Lemire $B,{ }^{1}$ Foisy $M$

${ }^{1}$ McGill University Health Centre, Montréal, QC

${ }^{2}$ The Ottawa Hospital, Ottawa, ON

${ }^{3}$ Windsor Regional Hospital, Windsor, ON

${ }^{4}$ Centre Hospitalier de l'Université de Montréal, Montréal, QC

${ }^{5}$ St. Paul's Hospital, Vancouver, BC

${ }^{6}$ Regina General Hospital, Regina Qu'Appelle Health Region, Regina, SK ${ }^{7}$ Northern Alberta HIV Program, Alberta Health Services, Edmonton, AB

Background : Pharmacists with various roles are involved in the interdisciplinary care of HIV-infected patients. A survey of HIV healthcare professionals was developed to determine and prioritize factors requiring referral for clinical pharmacy services.

Objectives: To describe how HIV healthcare professionals perceive the relative importance of HIV pharmacist activities and to compare the pharmacists' perception to the perception of other healthcare professionals.

Methods: This descriptive cross-sectional survey study targeted Canadian HIV practitioners involved in interdisciplinary teams including pharmacists, physicians, nurses etc. Data was collected anonymously using Fluid Survey, a secure online survey, by a snowball sampling technique. Comparative statistics were done using Wilcoxon signedrank, chi-square or exact Fisher's tests.

Results: Of the estimated 335 emails requesting participation, 95 participants completed the survey (estimated response rate of 28\%). Of the 53 criteria that were investigated, 19 (36\%) were characterized as "very important" by more than $50 \%$ of respondents. Pharmacists had a tendency to attribute a greater importance to the evaluation of patients on complex treatment regimens $(\mathrm{p}=0.04)$, counselling for initiation in antiretroviral therapy $(\mathrm{p}=0.01)$, pregnancy $(\mathrm{p}=0.02)$ and pediatrics $(\mathrm{p}=0.02)$. Forty-five $(47 \%)$ respondents considered that the development of a screening tool would help identify high risk patients who require pharmacy consultation, while $71(76.3 \%)$ respondents believed that implementation of a screening tool could be easily integrated into daily practice.

Conclusion: This national survey likely reflects an adequate sample of HIV healthcare professionals across Canada. A large variety of pharmacist related activities were considered as "very important" by a majority of participants though the relative importance of activities differed between the healthcare professionals. The different perceptions of the role of an HIV pharmacist warrant the development of a short and simple screening tool to identify at risk patients for referral to pharmacy in order to optimize patient care.

\section{Predictors of Bacteremia in the Elderly}

Bannerman $H,{ }^{1}$ Walker SAN, ${ }^{1,2,3}$ Elligsen $M,{ }^{1}$ Walker SE, ${ }^{1,2}$ Palmay $L,{ }^{1}$ Jackson L, ${ }^{1,4}$ Williams $E^{4,5}$ Liu $B^{5}$

${ }^{1}$ Department of Pharmacy, Sunnybrook Health Sciences Centre, Toronto, ON ${ }^{2}$ Leslie Dan Faculty of Pharmacy, University of Toronto, Toronto, ON

${ }^{3}$ Division of Infectious Diseases, Sunnybrook Health Sciences Centre Toronto, ON

${ }^{4}$ Veterans Centre, Sunnybrook Health Sciences Centre Toronto, ON

${ }^{5}$ Faculty of Medicine, University of Toronto, Toronto, ON 
Background : Diagnosing infection in elderly patients is challenging because typical manifestations seen in younger adults are often more subtle, or nonexistent, in the geriatric population, resulting in a delayed diagnosis. A delay in diagnosis of bacteremia in geriatric patients occurs in $>20 \%$ of cases, and misdiagnosis occurs in $35 \%$.

Objectives: The objective of this study was to identify predictors of bacteremia in elderly patients to provide clinicians with a practical tool to aid in the diagnosis of bacteremia in the elderly to: 1) minimize unnecessary exposure to antimicrobials; and 2) improve early identification of elderly patients who require antibiotic treatment for bacteremia.

Methods: A retrospective chart review of patients $>80$ years old admitted to hospital over a 4-year period was conducted. One hundred and five bacteremic patients (cases) were matched to non-bacteremic controls for gender, age, hospital ward, length of stay, and date of stay on the matching unit. Bivariate logistic regression was used to identify laboratory and clinical parameters that were significantly associated with infection $(\mathrm{p}<0.05$; adjusted odds ratio $(\mathrm{OR}))$ and Classification and Regression Tree (CART) analysis was used to identify breakpoints for these parameters.

Results: Statistically significant parameters and their corresponding breakpoints that were determined to be associated with infection were maximum temperature $(\operatorname{Tmax})(>37.55 \mathrm{C})(\mathrm{OR}=42.575)$, neutrophils $(>7.95)(\mathrm{OR}=1.923)$, a change in level of consciousness $(\mathrm{LOC})(\mathrm{Yes}=1$, $\mathrm{No}=0)(\mathrm{OR}=1.571)$, blood urea nitrogen $(\mathrm{BUN})(>10.05)(\mathrm{OR}=1.359)$, glucose $(>7.35)(\mathrm{OR}=1.167)$, albumin $(\leq 33.5)(\mathrm{OR}=1.038)$ and alanine aminotransferase (ALT) $(>19.5)(\mathrm{OR}=1.005)$. The significant regression equation determined was: $\operatorname{Ln}($ odds of infection $)=-150.299+$ $3.751($ Tmax $)+0.654$ (neutrophils $)+0.452$ (change in LOC) + $0.307($ BUN $)+0.154$ (glucose) +0.038 (albumin $)+0.005($ ALT $)$.

Conclusions: The derived parameters, regression equation, and breakpoints may be useful in improving the predictive capability of diagnosing infection in patients $\geq 80$ years old and will be evaluated and further refined in a prospective study.

\section{Determination of Gentamicin Pharmacokinetics in Neonates to Develop Practical Initial Extended- Interval Dosing Recommendations}

Potvin $M,{ }^{1}$ Walker $S A N,{ }^{1,2,3}$ Elligsen $M,{ }^{1,3}$ Iaboni D, ${ }^{4}$ Walker $S E,{ }^{1,2}$ Palmay L, ${ }^{1,3}$ Findlater $C,{ }^{4}$ Seto $W,{ }^{2,5}$ Simor $A,{ }^{3,6} N g E^{4,6}$

${ }^{1}$ Department of Pharmacy, Sunnybrook Health Sciences Centre, Toronto, ON ${ }^{2}$ Leslie Dan Faculty of Pharmacy, University of Toronto, Toronto, ON ${ }^{3}$ Division of Infectious Diseases, Sunnybrook Health Sciences Centre, Toronto, ON

${ }^{4}$ Women and Babies Program, Sunnybrook Health Sciences Centre, Toronto, ON

${ }^{5}$ Department of Pharmacy, Hospital for Sick Children, Toronto, ON ${ }^{6}$ Faculty of Medicine, University of Toronto, Toronto, $O N$

Background: Despite safe and effective use of extended-interval dosing (EID) of aminoglycosides in other patient populations, no consensus exists regarding EID recommendations for neonates.

Objective: The objective of this study was to determine gentamicin pharmacokinetics in neonates, and develop initial $\mathrm{mg} / \mathrm{kg}$ dosing recommendations that optimize peak and trough concentration targets for conventional and EID regimens.

Methods: Patient demographics and steady-state gentamicin concentration data were retrospectively collected for 60 neonates. Mean pharmacokinetic values were calculated using first-order pharmacokinetic principles and multiple linear regression was performed to determine significant covariates of clearance $(\mathrm{Cl})$ and volume of distribution (Vd). A classification and regression tree (CART) analysis was performed to determine the existence of breakpoints for significant covariates. Monte Carlo Simulation (MCS) was used to identify optimal dosing recommendations for each CART-identified subgroup.

Results: Gentamicin $\mathrm{Cl}$ and $\mathrm{Vd}$ were significantly associated with weight at gentamicin initiation. CART-identified breakpoints for weight at gentamicin initiation were: $\leq 850 \mathrm{~g}, 851-1200 \mathrm{~g}$, and $>1200 \mathrm{~g}$. No significant difference in pharmacokinetics (elimination rate constant and $\mathrm{Cl}$ ) existed for neonates weighing $>1200 \mathrm{~g}$ versus $851-1200 \mathrm{~g}$, due to inadequate sample size ( $\mathrm{N}=14$ neonates) and weight range in the $>1200 \mathrm{~g}$ subgroup (range:1210-2789g; mean:1744g). This prohibited development of robust dosing recommendations and necessitated their exclusion from dosage development. MCS identified that $3-4 \mathrm{mg} / \mathrm{kg} / \mathrm{dose}$ administered every 48 hours for neonates weighing $\leq 850 \mathrm{~g}$, and every 24 hours for neonates weighing $851-1200 \mathrm{~g}$ provided the best probability of attaining conventional targets (peak:5-10mg/L, trough: $\leq 2 \mathrm{mg} / \mathrm{L}$ ). MCS identified that $8-9 \mathrm{mg} / \mathrm{kg} / \mathrm{dose}$ administered every 72 hours in neonates weighing $\leq 850 \mathrm{~g}$ and every 48 hours in neonates weighing $851-1200 \mathrm{~g}$ provided the best probability of attaining EID targets (peak: $12-20 \mathrm{mg} / \mathrm{L}$, trough: $\leq 0.5 \mathrm{mg} / \mathrm{L}$ ).

Conclusions: In conclusion, this study provides initial dosing recommendations for conventional and EID regimens in neonates weighing $\leq 1200 \mathrm{~g}$. Further studies are needed to prospectively evaluate these dosing recommendations and to identify dosing recommendations in neonates weighing $>1200 \mathrm{~g}$.

\section{Impact of Length of Stay on the Distribution of Gram Negative Organisms and the Likelihood of Isolating a Resistant Organism in a Canadian Burn Centre}

Wanis $M,{ }^{1}$ Walker $S A N,{ }^{1,2,3}$ Daneman $N,{ }^{3,4,5,6}$ Elligsen $M,{ }^{2}$ Palmay $L,{ }^{2}$ Simor $A, 3,4,5,6$ Cartotto $R^{7}$

${ }^{1}$ Leslie Dan Faculty of Pharmacy, University of Toronto, Toronto, ON ${ }^{2}$ Department of Pharmacy, Sunnybrook Health Sciences Centre, Toronto, ON ${ }^{3}$ Department of Microbiology and Division of Infectious Diseases,

Sunnybrook Health Sciences Centre, Toronto, ON

${ }^{4}$ Faculty of Medicine, University of Toronto, Toronto, $O N$

${ }^{5}$ Sunnybrook Research Institute, Toronto, $O N$

${ }^{6}$ Institute for Clinical Evaluative Sciences, Toronto, ON

${ }^{7}$ Ross Tilley Burn Centre, Sunnybrook Health Sciences Centre, Toronto, ON

Background : Infection is a common complication in burn injury patients. The impact of hospital length of stay (LOS) on the distribution and susceptibility of Gram negative bacteria (GNB) causing infection in burn patients remains unexplored.

Objectives: To characterize the distribution of GNB causing infection and to identify changes in susceptibility with LOS in a tertiary care burn centre.

Methods: A retrospective review of patients with documented positive clinical (non-screening) GNB cultures identified from the antimicrobial stewardship program database was completed. Duplicate cultures were excluded. Positive cultures included in the analysis were categorized into five clinically relevant time periods (in days) based on the specimen date of collection relative to the patient's date of admission: A (0-7), B (7-14), C (14-21), D (21-28), E (>28). Chi-square for proportions was used to compare the 5 time periods. When the $\chi^{2}$ p-value was $<0.05$, the Marascuilo procedure was used to identify where the significant difference(s) between the 5 time periods occurred.

Results: The proportion of patients with clinical cultures for P.aeruginosa increased with hospital LOS (period 0-7 days: $8 \%$ vs period $>28$ days: 55\%; $\mathrm{p}<0.05$ ). Conversely, clinical cultures for H.influenzae occurred most commonly within the first 7 days of hospitalization (period 0-7 days: $36 \%$ vs period $>28$ days: $0.7 \%$; $<<0.05$ ). The proportion of 
Enterobacteriaceae isolation was highest between 7-14 day of hospitalization and lowest when LOS > 28 days (period 7-14 days: 62\% vs. period > 28 days: $38 \%$; $\mathrm{p}<0.05$ ). Resistance to antibiotics was directly proportional to hospital length of stay (\% patients with multidrug resistant GNB increased from 6\% (LOS 0-7days) to 44\% (LOS $>$ 28days); $\mathrm{p}<0.05$ ).

Conclusions: This study provides objective evidence illustrating changes in species and resistance patterns of GNB causing infection in burn injury patients as a function of hospital length of stay.

\section{Customization and Implementation of a Compounding Software Solution for Safe and Efficient Sterile and Non-sterile Compounding

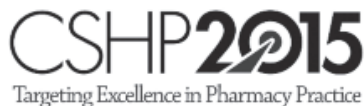

Perks B, Bains A, Vidotto S, DeFigueiredo S, Cotter N, Rideout T, Lye $M$, Chow L, Walker SE

Department of Pharmacy, Sunnybrook Health Sciences Centre, University of Toronto, Toronto, ON

Background : The number and potential consequences of error and workload in a busy Hospital Pharmacy compounding centre were reviewed. Root cause analysis pointed to potential problems caused by: multiple versions of worksheets; manual systems for labeling; lack of a weight check system; lack of barcode ingredient verification.

Description: A solution was sought to: Secure master formulation documents; ensure weights were accurate; ensure ingredients used were correct; automatically generate worksheets/labels thereby minimizing errors and improving productivity.

Action: A specifications document was developed outlining the required functionality. This was created through a literature search; internet search; discussion with medication safety and Pharmacy staff. Options explored were an in-house or external vendor custom solution; external customization of off-the-shelf software and internal customization of off-the-shelf software. The latter was decided upon as the most costeffective end feasible alternative which allowed introduction of the barcode verification feature.

Evaluation: The time to implement the solution was roughly one year from inception. One-time expenditures on software and hardware were approximately $\$ 10,000$. Non-sterile compounding using the implemented software solution resulted in a reduction of labelling errors from $0.5 \%$ to $0 \%$. Use of the software solution allows for an $80 \%$ time reduction in the administrative elements of compounding (Lot Number creation, Beyond Use Date Assignment, Worksheet Printing, Label Printing) (5 minutes vs 1 minute). Errors due to incorrect "picking" of ingredients are nearly impossible with the barcode scanning verification feature.

Implications: A dedicated, customized compounding software solution improves productivity and reduces the chance of errors in compounding. Productivity gains and cost-effectiveness in any particular environment will depend on volume of compounding. Labelling and Beyond Use Date assignment errors can be reduced to practically zero. Customization and implementation of a compounding software solution is achievable utilizing existing in-house Pharmacy resources.

\section{Correlation between Length of Smoking Cessation Therapy and Rate of Abstinence in Pragmatic Conditions}

\section{CSHP29) \\ Targeting Excellence in Pharmacy Practice}

Lui K, MaJ

Canadian Forces Health Services Group, Petawawa, ON

Background: In May 2012, a multidisciplinary smoking cessation support program was implemented, aimed to enhance patient access and convenience. The program consisted of weekly clinics run by pharmacists, physicians, and the health promotions team. A drug use evaluation was done as an initial program assessment and demonstrated that the new program increased uptake of smoking cessation therapy compared to the same six-month timeframe in the preceding year, though with a marked decrease in the duration patients were on pharmacotherapy. The significance of these observations on rate of success in smoking cessation, however, is unknown. Existing literature suggests a positive correlation between duration of therapy and the rate of abstinence at one year in trial conditions. This relationship in a clinical setting is not well understood.

Objective: To describe the relationship between duration of smoking cessation pharmacotherapy and rate of success in smoking cessation in pragmatic conditions.

Method: A retrospective analysis was conducted using dental and dispensing records of patients who expressed interest in smoking cessation to a health care team member from June to December 2011 and June to December 2012. Specifically, patients' smoking status at the annual dental exam in the calendar year following their smoking cessation attempt was compared against their time spent on pharmacotherapy, estimated by the number of days between the first and last fill of their smoking cessation medication.

Results

\begin{tabular}{|c|c|c|c|c|c|c|}
\hline & $\begin{array}{l}\text { Number of } \\
\text { patients } \\
\text { initiating } \\
\text { smoking } \\
\text { cessation } \\
\text { pharmacotherapy }\end{array}$ & $\begin{array}{l}\text { Smoking } \\
\text { status at } \\
\text { annual dental } \\
\text { exam }\end{array}$ & $\begin{array}{l}\text { Dental } \\
\text { record } \\
\text { not } \\
\text { available }\end{array}$ & $\begin{array}{l}\text { Average } \\
\text { number of } \\
\text { days spent on }\end{array}$ & $\begin{array}{l}\text { Standard } \\
\text { deviation }\end{array}$ & $\begin{array}{l}\text { Time spent } \\
\text { on pharmaco- } \\
\text { therapy not } \\
\text { available }\end{array}$ \\
\hline \multirow[t]{2}{*}{2011} & 187 & $\begin{array}{ll}\text { Yes } & 124 \\
& (66 \%)\end{array}$ & 1 & 33.37 & 43.16 & 4 \\
\hline & & $\begin{array}{ll}\text { No } & 62 \\
& (33 \%)\end{array}$ & & 33.37 & 42.97 & \\
\hline \multirow[t]{2}{*}{2012} & 317 & $\begin{array}{l}227 \\
(71 \%)\end{array}$ & 2 & 31.67 & 30.85 & 6 \\
\hline & & $\begin{array}{ll}\text { No } & 88 \\
& (27 \%)\end{array}$ & & 31.92 & 30.93 & \\
\hline
\end{tabular}

Conclusion: We were unable to observe differences in length of therapy between those with successful attempts versus those unsuccessful. Although a multidisciplinary program was implemented in 2012, the results were similar to 2011. Our multidisciplinary approach did not impact the relationship. 